Utah State University

DigitalCommons@USU

\title{
$5-2016$
}

\section{Effect of Chronic Administration of Oxytocin on Corpus Luteum Function in Cycling Mares}

Katherine Clissold Parkinson

Utah State University

Follow this and additional works at: https://digitalcommons.usu.edu/etd

Part of the Animal Sciences Commons

\section{Recommended Citation}

Parkinson, Katherine Clissold, "Effect of Chronic Administration of Oxytocin on Corpus Luteum Function in Cycling Mares" (2016). All Graduate Theses and Dissertations. 4726.

https://digitalcommons.usu.edu/etd/4726

This Thesis is brought to you for free and open access by the Graduate Studies at DigitalCommons@USU. It has been accepted for inclusion in All Graduate Theses and Dissertations by an authorized administrator of DigitalCommons@USU. For more information, please contact digitalcommons@usu.edu.

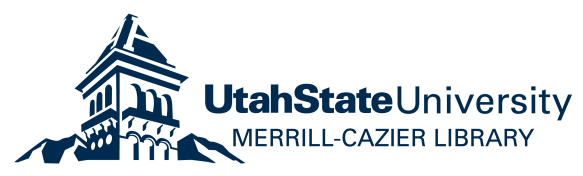


EFFECT OF CHRONIC ADMINISTRATION OF OXYTOCIN ON CORPUS

LUTEUM FUNCTION IN CYCLING MARES

by

Katherine Clissold Parkinson

A thesis submitted in partial fulfillment

of the requirements for the degree

of

MASTER OF SCIENCE

in

Animal, Dairy, and Veterinary Sciences

Approved:

Dr. Dirk K. Vanderwall

Major Professor

Dr. Kerry Rood

Committee Member
Dr. S. Clay Isom

Committee Member

UTAH STATE UNIVERSITY

Logan, Utah

Dr. Mark R. McLellan

Vice President for Research and

Dean of the School of Graduate Studies 
Copyright (C) Kate Parkinson 2016

\section{All Rights Reserved}




\begin{abstract}
Effect of Chronic Administration of Oxytocin on Corpus Luteum Function in Cycling Mares

by

Katherine Clissold Parkinson, Master of Science

Utah State University, 2016
\end{abstract}

Major Professor: Dr. Dirk K. Vanderwall

Department: Animal, Dairy, and Veterinary Sciences

Undesirable and variable behavior in mares related to the estrous cycle is a common issue reported in the equine industry, especially for mares in a performance setting. These behaviors can interfere with, as well as decrease, overall performance. The objective of this study was to determine if administration of sixty units of oxytocin once daily for 29 days, regardless of when treatment was initiated during the estrous cycle, would induce prolonged corpus luteum (CL) function in cycling mares. Mares were randomly assigned to two groups: 1) saline-treated control ( $\mathrm{n}=7)$ and 2) oxytocintreated $(\mathrm{n}=9)$. Control mares received $3 \mathrm{cc}$ saline and oxytocin-treated mares received sixty units $(3 \mathrm{cc})$ of oxytocin intramuscularly (IM) for 29 consecutive days. Treatment was initiated in all mares on the same day, independent of the day of the cycle. Jugular blood samples for determination of progesterone concentration were collected three times weekly $(\mathrm{M}, \mathrm{W}, \mathrm{F})$ for 21 days before treatment was initiated. Beginning on the first day of treatment, blood samples were collected daily for seven days, three times weekly for 
the remainder of the treatment period, and then three times weekly for 45 days after the last treatment. Mares were considered to have prolonged CL function if serum progesterone remained $>1.0 \mathrm{ng} / \mathrm{mL}$ for at least 30 days during/after the treatment period. The proportion of mares with prolonged CL function was higher in the oxytocin-treated group compared to the saline-treated group ( $7 / 9$ vs. $1 / 7$, respectively; $\mathrm{P}<0.05)$. Three of the seven oxytocin-treated mares that developed prolonged CL function initially underwent luteolysis within three to seven days of the start of oxytocin treatment, and then developed prolonged CL function following the subsequent ovulation during the treatment period. In the other four oxytocin-treated mares that developed prolonged CL function, progesterone remained $>1.0 \mathrm{ng} / \mathrm{mL}$ throughout the treatment period and into the post-treatment period. All mares with prolonged CL function maintained elevated progesterone concentrations through at least day 56 of the study. Sixty units of exogenous oxytocin treatment for 29 consecutive days was effective in prolonging CL function as a means of estrus suppression in mares. 


\title{
PUBLIC ABSTRACT
}

\author{
Effect of Chronic Administration of Oxytocin on Corpus Luteum Function in Cycling \\ Mares \\ by \\ Katherine Clissold Parkinson, Master of Science \\ Utah State University, 2016
}

Undesirable and variable behavior in mares related to the reproductive cycle is a common issue reported in the equine industry, especially for female horses in a performance setting. These behaviors can interfere with and decrease, overall performance. The objective of this study was to determine if administration of 60 units of the hormone oxytocin once daily for 29 days, regardless of when treatment was initiated during the estrous cycle, would induce prolonged corpus luteum function in cycling mares. Mares were randomly assigned to two groups: 1) saline-treated control $(\mathrm{n}=7)$ and 2$)$ oxytocin-treated $(\mathrm{n}=9)$. Control mares received $3 \mathrm{cc}$ saline and oxytocintreated mares received 60 units $(3 \mathrm{cc})$ of oxytocin intramuscularly for 29 consecutive days. Treatment was initiated in all mares on the same day (day 1), independent of the day of the cycle. Jugular blood samples for determination of progesterone concentration were collected three times weekly (M, W, F) for 21 days before treatment was initiated. Beginning on the first day of treatment, blood samples were collected daily for seven days, three times weekly for the remainder of the treatment period, and then three times weekly for 45 days after the last treatment. Mares were considered to have prolonged CL function if serum progesterone remained $>1.0 \mathrm{ng} / \mathrm{mL}$ for at least 30 days during/after the treatment period. The proportion of mares with prolonged CL function was higher in the 
oxytocin-treated group compared to the saline-treated group (7/9 vs. 1/7, respectively; $\mathrm{P}<0.05)$. Three of the seven oxytocin-treated mares that developed prolonged $\mathrm{CL}$ function initially underwent luteolysis within three to seven days of the start of oxytocin treatment, and then developed prolonged CL function following the subsequent ovulation during the treatment period. In the other four oxytocin-treated mares that developed prolonged CL function, progesterone remained $>1.0 \mathrm{ng} / \mathrm{mL}$ throughout the treatment period and into the post-treatment period. All mares with prolonged CL function maintained elevated progesterone concentrations through at least day 56 of the study. Sixty units of exogenous oxytocin treatment for 29 consecutive days was effective in prolonging CL function as a means of estrus suppression in mares. 


\section{ACKNOWLEDGMENTS}

I would like to express my deep gratitude for everyone who has been involved with and has supported me on this journey. I have had an incredible support system, which has made this experience an enjoyable ride. First and foremost, I'd like to thank my husband, Jason, for his constant support and encouragement. He has stood beside me during this process, lending a listening ear, helping hand, and much needed comic relief. Without complaint, he helped me with the mares at the farm and everything from holding troublesome mares while I drew blood, to being the personal farrier for all the research mares. He has patiently listened to me think out loud, bounce ideas off him, and tolerated the many late nights of reading and typing. I would also like to thank my parents, siblings and in-laws for their constant encouragement, understanding, and support. Specifically, I really appreciate my parent's sincere interest in my research and schooling. They have always taught me to work hard in school and achieve my goals. I would like to thank them for being so supportive of my decision to pursue a graduate degree and their genuine interest in hearing about my research or what new fact I had learned. I'm grateful to them for helping me learn the value of education and encouraging me to step out of my comfort zone.

I am truly grateful for the wonderful help I had during the course of this project. I couldn't have done all the work at the farm or in the lab by myself. I would like to express my gratitude to Bettina Conrad for her help and patience in the lab, teaching me how to work the machinery and answering my many questions. I would also like to thank Sherrie Petty and Lexi Sweat with their assistance with the mares. Their help at the 
farm handling the mares was much appreciated. Lexi went especially above and beyond with her support and I am truly grateful for her friendship. She spent many extra hours helping me and has kept in touch, requesting updates, even though she has moved on with her own education

I would like to thank my committee members for their guidance and support in my education. I had the unique opportunity to have Dr. Isom and Dr. Rood as my professors as an undergrad as well as graduate student and their individual support and interest in my education is appreciated. I want to thank Dr. Rood for his constant encouragement. He always left me with an encouraging word when I needed it and pushed me to do hard things. I am grateful for Dr. Isom for his willingness to be on my committee and always making time for me, even when he was busy. I would also like to thank Dr. Rickords. Although he was not formally on my committee, I am extremely appreciative of time he spent answering my questions and I'm grateful to him for always making time for me. Finally, I would like to express my deep gratitude to Dr.

Vanderwall. I am lucky to have a major professor that personally invested so much time in teaching me. I am extremely fortunate to have learned from his vast knowledge and expertise, and am deeply grateful for his time and effort, which he so willingly invested in my education. I will always be thankful for his kind nature and never making me feel like a bother, even with his busy schedule. I am grateful for the many hours spent helping me with the scientific writing process and for his encouragement to step out of my comfort zone and grow as a student and professional. I will be forever grateful for his role in making my educational experience exceptional. 


\section{CONTENTS}

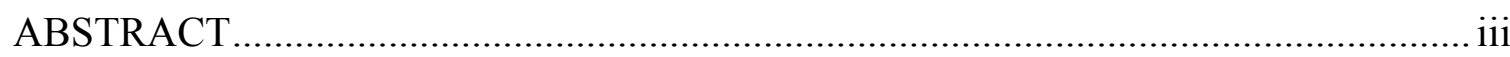

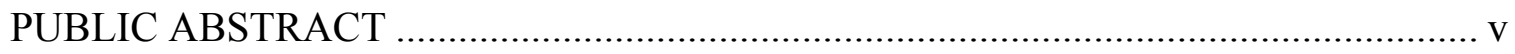

ACKNOWLEDGMENTS ............................................................................... vii

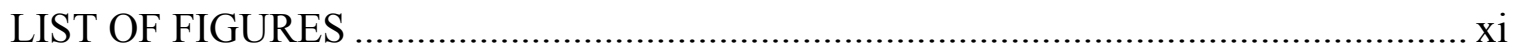

LIST OF ABBREVIATIONS ............................................................................. xii

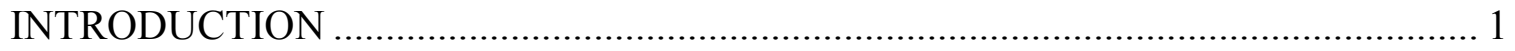

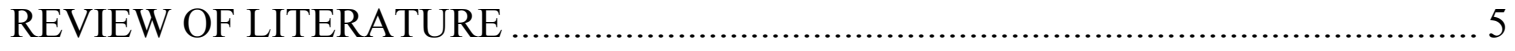

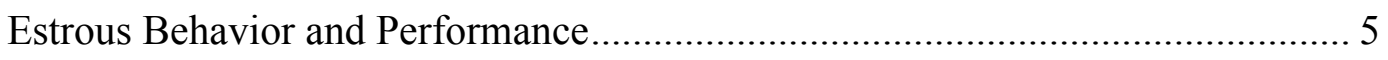

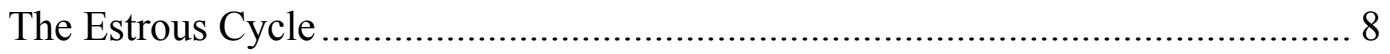

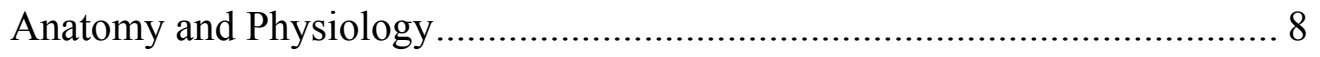

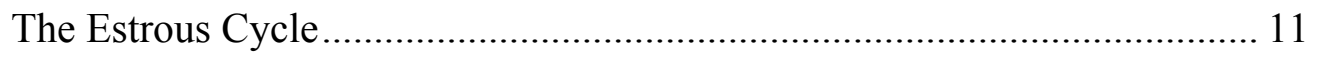

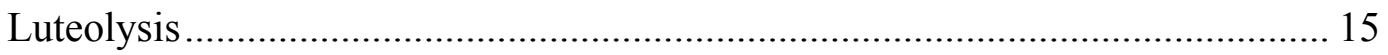

Uterine Role in Luteolysis .................................................................. 15

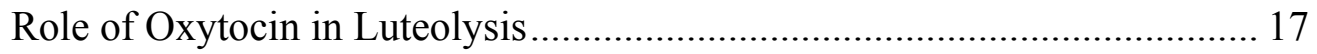

Prolonged Luteal Function..................................................................... 21

General Methods of Estrus Suppression ..................................................... 22

Hormonal Methods and Methods of Prolonging Function of the CL .................. 23

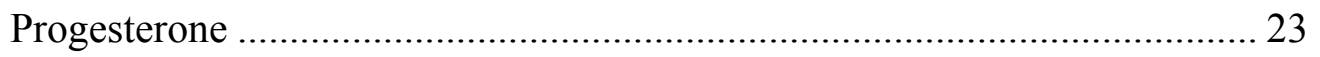

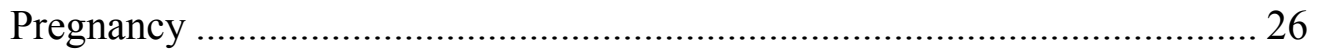

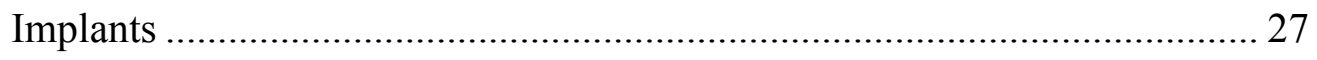




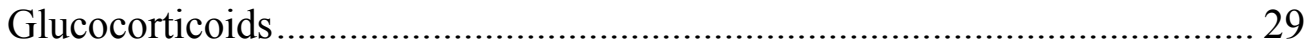

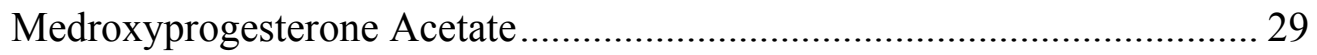

Induction of a Late-Diestrus Ovulation .................................................... 30

Uterine Infusion of Plant Oils................................................................ 31

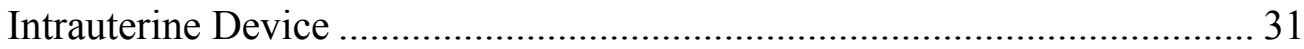

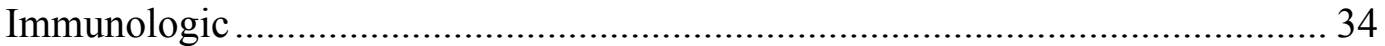

GnRH Vaccine ................................................................................ 34

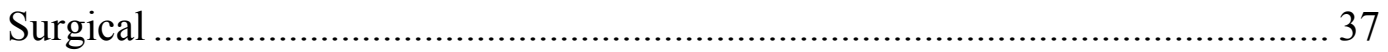

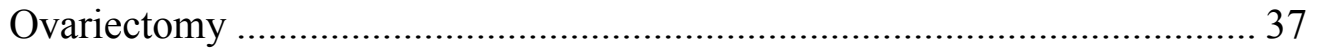

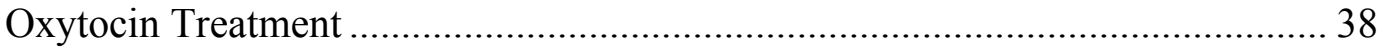

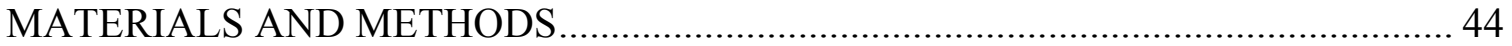

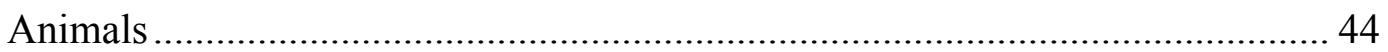

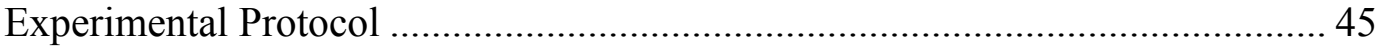

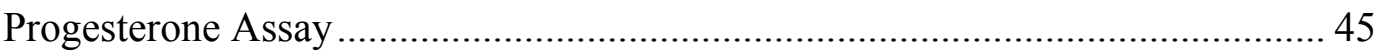

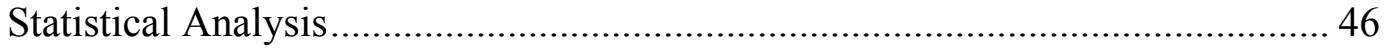

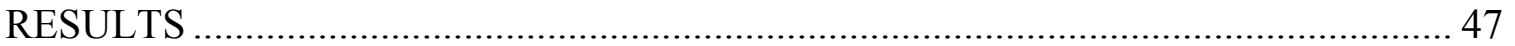

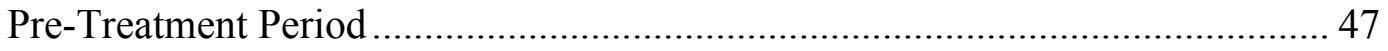

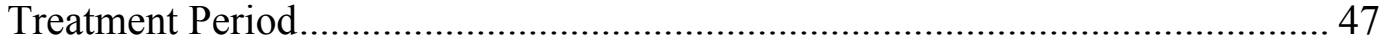

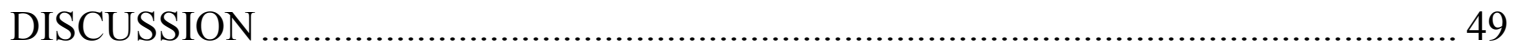

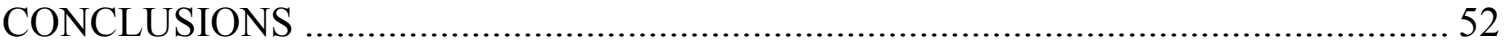

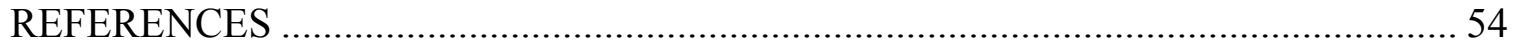




\section{LIST OF FIGURES}

Figure $\quad$ Page

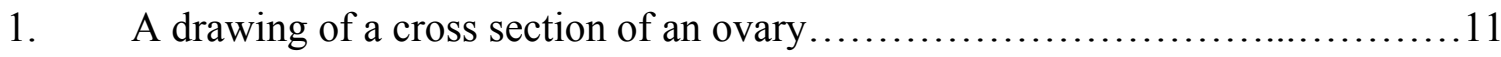

2. Seasonal influences on the hormonal and behavioral interactions associated with the HPO axis........................................................13

3. Hormonal profiles and associated ovarian activity during the equine estrous cycle........................................................... 14

4. Serum progesterone levels of control mares during and after the treatment

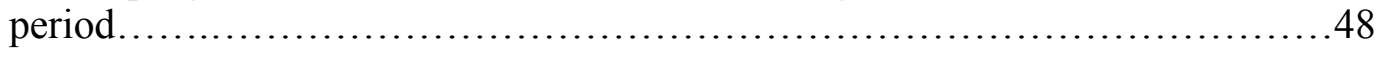

5. Serum progesterone levels of oxytocin treated mares during and after the

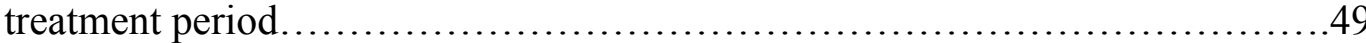




\section{LIST OF ABBREVIATIONS}

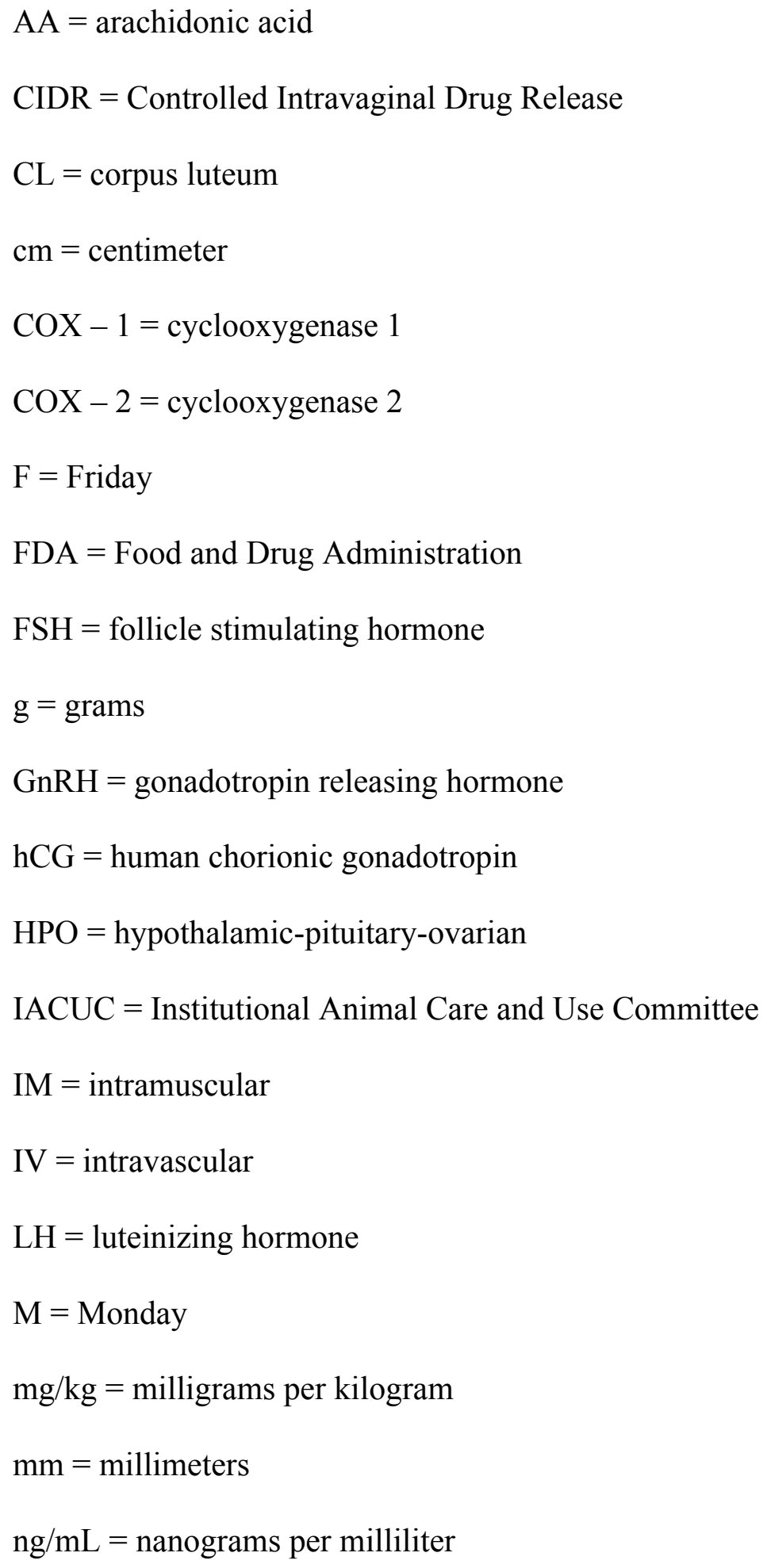


$\mathrm{MPA}=$ medroxyprogesterone acetate

PGF $2 \alpha=$ prostaglandin F2 $\alpha$

PGFM $=13,14$-dihydro-15-keto PGF2 $\alpha$

$\mathrm{PLA}_{2}=$ phospholipase $\mathrm{A}_{2}$

PGFS $=$ prostaglandin F synthase

$\mu \mathrm{l}=$ microliter

$\mathrm{W}=\mathrm{Wednesday}$ 


\section{INTRODUCTION}

A common complaint of veterinarians, horse owners, and trainers is the variable behavior and performance of mares that is related to the estrous cycle (Jorgensen et al., 1996). Because of that, suppression of estrous behavior has become a common practice in performance mares and the most widely used methods include: 1) administration of exogenous progesterone/progestins 2) extending the duration of corpus luteum (CL) function, 3) suppressing ovarian follicular activity, and 4) ovariectomy (Vanderwall and Nie, 2011). Of these methods, the most commonly used are administration of exogenous progesterone/progestins and prolonging the life of the CL.

Administration of altrenogest (ReguMate ${ }^{\circledR}$, Merck Animal Health), an orally active synthetic progestin, is approved, widely used, and is effective in suppressing estrous behavior. The use of ReguMate is considered the "gold standard" of estrus suppression in the equine industry. Unfortunately, the dose of 0.044 milligrams per kilogram $(\mathbf{m g} / \mathbf{k g})$ is needed daily, and other drawbacks such as expense, need for long term administration, and safety concerns of personnel during handling and dosing are drawbacks to its use (Squires et al., 1979; Vanderwall, 2012). Another drawback exists in the fact that because altrenogest is a steroid, it is under increased scrutiny for administration to animals in performance settings and is not permitted in some countries (Hedberg et al., 2006). It has been reported that an alternative intramuscular (IM) administration of compounded preparation of $225 \mathrm{mg}, 450 \mathrm{mg}$, or $500 \mathrm{mg}$ of altrenogest blocked estrous behavior for 12, 15, and 30 days respectively (Storer et al., 2009). Compounded products, however, can vary in potency and stability, thus results can also 
vary. The use of a compounded preparation of altrenogest when a Food and Drug Administration (FDA) approved product such as Regumate ${ }^{\circledR}$ is available may not be appropriate, and is not long term enough to be considered an optimal method for estrus suppression. In an effort to eliminate the inconvenience of daily administration, growthpromoting implants containing progesterone and estradiol labeled for use in cattle have been anecdotally reported to be effective. When tested in horses under controlled conditions, the treated horses failed to produce serum progesterone levels above 0.5 nanograms per milliliter (ng/mL) and did not suppress estrous behavior (McCue, 1997).

An alternative to administration of exogenous progesterone and another common method of estrous suppression is induction of prolonged CL function. This allows for endogenous secretion of progesterone from the CL to block estrous behavior. In cycling mares, the CL secretes progesterone for approximately two weeks, during which progesterone levels are high. The CL stops functioning when prostaglandin F2 $\alpha$ (PGF2 $\alpha$ ) is secreted by the endometrium during luteolysis (Ginther, 2012). There is interest in developing methods of prolonging luteal function as a means of estrus suppression because it allows for the natural secretion of progesterone, rather than the supplementation of exogenous progesterone/progestins.

There are many methods of inducing prolonged CL function, but the most widely used method has been insertion of an intrauterine glass ball. In a study by Nie et al. (2003), placement of a $25-35 \mathrm{~mm}$ sterile glass ball into the uterus following an ovulation resulted in prolonged CL function in 7 of 18 (39\%) of mares. In the control group, four of 32 mares (13\%) spontaneously prolonged CL function. It is important to note that while insertion of an intrauterine glass ball seems effective, three of the seven mares in 
the treatment group that prolonged luteal function had one or two estrous cycles after placement of the glass ball, followed by prolonged CL function. As a result, the "percycle" basis of prolonged CL function was 7/62 cycles (11\%) and compared to the $4 / 50$ cycles $(8 \%)$ in non-treated control mares, and that was not significantly different between groups. Placement and removal of the intrauterine marble must be done by a veterinarian when the mare is in late estrus, close to ovulation. Removal must also be done by a veterinarian, which is a drawback to this method. There have also been reports of spontaneous fragmentation of the glass ball in the uterine lumen causing deleterious consequences (LeBlanc, 2011). Because of its variable efficacy, placement of an intrauterine glass ball does not seem to be a desirable method for suppression of estrus in mares, thus the need for a safe, practical, and effective method of prolonging CL function.

There are numerous other methods of estrus suppression, however, each of the methods has different disadvantages that create a need for more research in the field. Issues such as cost, reversibility, etc. are also reason for further research. The industry is in need of a safe, effective, and reliable method of estrus suppression.

Recently, administration of oxytocin has been shown to be an effective method of prolonging CL function, since administration of 60 units of oxytocin once daily on days 7 to 14 after ovulation induced prolonged CL function in over $60 \%$ of treated mares (Vanderwall et al., 2012b). However, the need to know the exact day of ovulation is a drawback to the current oxytocin protocol. We hypothesized that by extending the duration of oxytocin administration, treatment could be initiated at any point during the estrous cycle (i.e., without knowing the day of ovulation) and still effectively prolong CL 
function. Therefore, the objective of this study was to determine if treating mares with oxytocin daily for 29 days would result in prolonged CL function. 


\section{REVIEW OF LITERATURE}

The effect of the mare's estrous cycle on behavior and performance is an important issue for the equine industry. Specifically, concern over the potential for estrous behavior to adversely affect performance has led to the common practice of estrus suppression. Though there are many methods of estrus suppression that are currently being used, there is a definite need for better options. It is the purpose of this review to examine the complexities of the equine estrous cycle; its effects on performance and behavior; and the advantages and disadvantages of the general methods of estrus suppression that are currently being used. It will also address the need for new options of estrus suppression and how the use of exogenous oxytocin treatment is effective and advantageous to the industry.

\section{Estrous Behavior and Performance}

Suppression of estrus in mares has become a growing necessity within the equine industry. The behaviors associated with estrus have been reported to have a negative effect on the training and showing of horses in many disciplines (McCue, 2003). Today, horses are expected to perform at a very high level of skill and the horse's disposition is a very important factor in its ability to perform (Hedberg et al., 2005). Veterinarians, trainers, and horse owners all complain of negative performance in mares that is related to the estrous cycle. A survey of more than 750 veterinarians reflected that approximately $90 \%$ feel that the estrous cycle affected the performance of mares, with the most frequent clinical sign being reported as a change in attitude. The behaviors associated with the estrous cycle can include biting, kicking, tail swishing, difficulty to 
train, squealing, "horsing", excess urination and a decrease in performance (Jorgensen et al., 1996).

It is important to confirm that the observed behavioral problem is, in fact, associated with the reproductive cycle of the mare before initiating treatment, as not all of the previously mentioned behaviors are necessarily associated with estrus. Some behaviors thought to be associated with estrus can instead be signs of submissive behavior, stallion-like behavior, or urogenital discomfort (McDonnell, 1993; McDonnell, 2000). Submissive behavior can be mistaken for behaviors related to estrus and usually include leaning away from perceived threats, squirting urine, and wringing of the tail. Behaviors truly associated with estrous include leaning towards the stallion, relaxed lifting motion of the tail, dribbling urine, or a squatting stance (McDonnell, 2000). Urogenital discomfort can result in behaviors mistaken for estrus, but are typically a result of cystitis or renal disease instead. Stallion-like behavior may be a result of neoplasia of the ovaries or the administration of exogenous anabolic steroids (Vanderwall, 2013). In an effort to correctly diagnose the complaint of estrus-related behavior or performance issues related to the reproductive cycle, it is important to take into consideration different factors when determining the source and subsequent treatment. It is important to determine if the undesirable behavior is from a reproductive or nonreproductive source followed by determining if the behavior is associated with a specific phase of the estrous cycle (McDonnell, 2005).

If the behavior can be pinpointed to a specific phase, then determining if the behavior is physical or behavioral is necessary. Accurate records are needed to aid in determining the phase of the reproductive cycle during which the behavior occurs. A 
physical examination is also necessary in order to rule out other contributing medical problems (McCue, 2003). At certain points of the estrous cycle, mares can exhibit behavior related to pain or discomfort during the preovulatory period. During this period, the mare has a large ovarian follicle present on the ovary, causing discomfort prior to ovulation in some mares. This discomfort can cause sensitivity to the weight of a rider and can vary in severity from subtle to more severe colic-like symptoms (Cox and DeBowes, 1987; Pryor and Tibary, 2005). The use of an ovulatory agent can be beneficial for mares experiencing pain due to a large follicle by shortening the time it is present. (Vanderwall, 2013).

Not all mares have compromised performance from underlying physical causes during estrus. Some mares have such profound signs of estrus that the behavior alone affects performance. This can be seen in instances where the animal is under saddle and displays "break down" behavior showing estrus in response to nearby horses or other stimuli. This behavior can include a squatting-like pose and the mare will become difficult to move away from the stimulus (McDonnell, 2000). Behaviors such as this may not always be evident and can be much subtler. Owners and trainers have reported that the mare can be simply less attentive or cooperative during estrus, creating difficulty for training and showing purposes (McDonnell, 1997).

In some cases, mares display abnormal estrous behavior and exhibit signs of estrus during the anovulatory season, silent estrus, or split estrus. Split estrus can be defined as a period during normal estrus with alternating days of receptivity to the stallion. The mare may be receptive one day and non-receptive the next. This is typical in approximately $5 \%$ to $12 \%$ of mares (Asa, 1986; Ginther, 1992). Silent estrus is 
characterized by the incidence of ovulation without the subsequent behavior reported in conjunction with estrus. This phenomenon occurs in 6\%-7.5\% of the cycles (Cummings, 1942; McCaughey et al., 1973).

There are numerous situations in which the behaviors associated with the estrous cycle create difficulty for horse owners, trainers, and veterinarians. Some mares become more difficult than others, and as stated above, there are many situations that differ in severity. Overall, the effect of ovarian activity in the mare, specifically in the phase of estrus, has been considered a factor in the decreased performance of the mare (Pryor and Tibary, 2005). For these circumstances, estrus suppression is recommended.

\section{The Estrous Cycle}

In order to better understand the necessity of suppression of some behaviors related to the estrous cycle, a comprehensive review of mare reproductive anatomy and physiology, in addition to an explanation of the estrous cycle is warranted.

\section{Anatomy and Physiology}

To understand the physiology of the mare's reproductive system and estrous cycle, it is important to understand some basics of reproductive anatomy of the horse. The major female reproductive organs include the ovaries, internal tubular genitalia (oviducts, uterus, cervix, vagina, and vestibule) and external genitalia (vulva and labia), as well as the mammary glands. The normal function of these structures is dependent on hormones and interactions with their appropriate receptor. The neuroendocrine hormones that are produced or secreted mainly from the hypothalamus and pituitary gland are especially important. Feedback mechanisms between the central nervous system and 
reproductive organs allow for communication among themselves, thus the endocrine system plays an important role in regulating and modulating the reproductive events that occur in the mare (Samper, 2009).

The ovaries include the following structures: follicles, corpora lutea, and oocytes. These structures are all important to the cyclicity of the mare. During development, the ovaries develop near the kidneys and have only migrated slightly in adulthood. The ovaries are approximately $4-8$ centimeters $(\mathbf{c m})$ in length, $3-6 \mathrm{~cm}$ in width, and $3-5 \mathrm{~cm}$ in height. They lie near the kidneys in the dorsal part of the abdomen, near the iliac wings of the hip. The left ovary is typically more caudal than the right, a result of the left kidney also being more caudal. In prepubertal fillies, the ovaries are oval with the cortex and germinal epithelium being superficial. As the filly approaches puberty, the ovary transforms into a kidney bean shape. This is a result of the ovarian cortex invaginating into the medulla (Samper, 2009). The ovaries occur bilaterally, adjacent to the distal end of each uterine horn.

Within the ovary, structures known as follicles are present. These follicles occur in a variety of stages including growing, ovulating, anovulatory hemorrhagic, and regressing. Follicular development in the ovaries occurs in a wave-like fashion through the different stages of the estrous cycle, seasonal transition, and pregnancy (Ginther, 1992; Ginther et al., 2004)

During the physiological breeding season (i.e., ovulatory season) waves of follicular development can be classified as major or minor waves, with the major waves being further classified as primary or secondary. This distinction is based on whether the largest follicle produced in a wave reaches $\geq 30$ millimeters ( $\mathbf{m m}$ ) or $<30 \mathrm{~mm}$. Both 
waves have a growth phase in which a group of follicles begins. Only major waves display selection of a dominant follicle, while minor waves lack a dominant follicle and, therefore, no selection. Major primary waves, also known as ovulatory, are associated with the follicular phase, or estrus. Major secondary waves, which can be ovulatory or anovulatory, or minor waves are typically associated with the luteal phase, or diestrus. Mares in transition (spring or fall) will typically display a combination of anovulatory major follicles and minor follicular waves. In a typical follicular wave during the estrous cycle, 5-10 follicles $(4-6 \mathrm{~mm})$ will develop within 2-3 days of each other. These follicles will increase in size by $2-4 \mathrm{~mm} /$ day until the largest reaches $20-25 \mathrm{~mm}$, signaling the end of the growth phase. Following the growth phase, numerous outcomes can occur. In a minor wave, all of the follicles will regress, but in the case of a major wave, all but one of the follicles will regress. As the subordinate follicles decrease in diameter, the dominant follicle increases in diameter until it ovulates, becomes anovulatory, or regresses (Samper, 2009).

After ovulation, the process of follicular rupture and release of the oocyte, the site of the dominant follicle begins to fill in with luteal cells. This process is called luteinization and involves the morphogenesis of estrogen producing cells of the follicle into progesterone-producing luteal cells that make up the CL (Figure 1; Ginther, 1992). The CL plays a significant role in the estrous cycle of the mare, with its main function being the secretion of progesterone. In non-pregnant mares, the CL secretes progesterone for approximately two weeks after ovulation, or the duration of diestrus. The CL ceases function when the endometrium secretes PGF2 $\alpha$ and luteolysis occurs (Ginther, 2012). Artificially induced luteolysis is possible using PGF2 $\alpha$ treatment (Samper, 2009). 


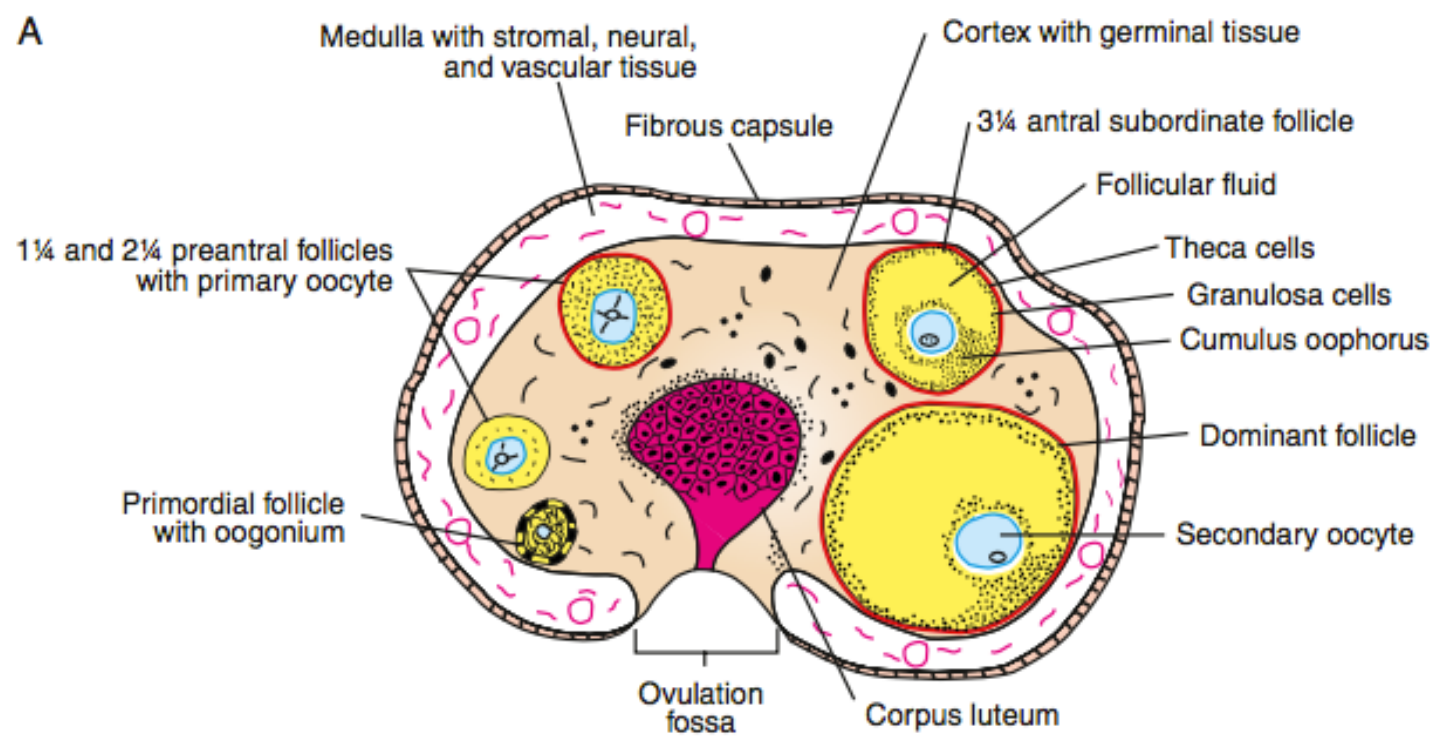

Figure 1. A drawing of a cross section of an ovary (Samper, 2009).

\section{The Estrous Cycle}

Mares are considered to be a seasonally polyestrous species and usually have a 20-22 day cycle during the breeding season. During this cycle, 14-15 days are in the luteal phase, also known as diestrus. Estrus, or the follicular phase, is typically observed for 5-7 days, but can range in variation from 3-12 days (Pryor and Tibary, 2005).

During the period of estrus, the mare is receptive to the stallion. Behavioral estrus occurs as a result of the circulating estrogen that is associated with the dominant follicle being developed in the ovary. Importantly, progesterone is low at this time, as progesterone overrides the effect of estrogen. The intensity of estrous behavior typically becomes stronger as ovulation approaches. This phenomenon of behavior corresponds with physiological events including the dominant follicle reaching maximum size, peak concentrations of estradiol 1-3 days before ovulation, and endometrial edema. After 
ovulation, estrous behavior will typically decrease simultaneously with the decrease in circulating estrogen, and the increase of circulating progesterone associated with the development of the CL occurs. It is typical for estrous behavior to continue for 1-2 days after ovulation (Samper, 2009).

Ovulation marks the end of one inter-ovulatory interval and the beginning of another. The time between ovulations is typically referred to as the interovulatory interval. The day of ovulation is referred to as Day 0 to serve as a point of reference and aid in the prescription of timed treatments (Samper, 2009).

The ovulatory season typically begins in response to an increase in day length. This change in light is recognized by photoreceptors in the eye and relayed to the pineal gland, where changes in melatonin secretion decrease, resulting in increased gonadotropin releasing hormone ( $\mathbf{G n R H})$ synthesis and secretion. GnRH then stimulates follicle stimulating hormone (FSH) and luteinizing hormone (LH) synthesis via the pituitary gland, which reaches the ovaries and stimulates follicular growth (Bergfelt, 2009). This interaction is known as the hypothalamic-pituitary-ovarian (HPO) axis (Figure 2). It is important to understand the HPO axis and the effect it has on progesterone and estrogen during the estrous cycle.

The high concentrations of circulating estradiol typically peak before ovulation. These levels of estradiol have a positive feedback on the HPO axis and an increase in LH during late estrus occurs as a result. The high concentrations of LH that occur are needed for the dominant follicle to continue growing and also serves as a signal for the coming ovulation of the follicle (Bergfelt and Adams, 2007). At the time of ovulation, FSH is low as a result of the negative synergistic effect of inhibin and estradiol (Samper, 2009). 
It will begin to rise as LH and follicular inhibin fall after ovulation. LH is still needed in low magnitude surges for growth and maturation of the CL and increases circulating progesterone. Follicle stimulating hormone and progesterone will remain high during diestrus and the presence of the CL, but will decrease near the end of diestrus as the CL regresses and undergoes luteolysis (Figure 3).

\section{Hypothalamic-Pituitary-Ovarian axis}

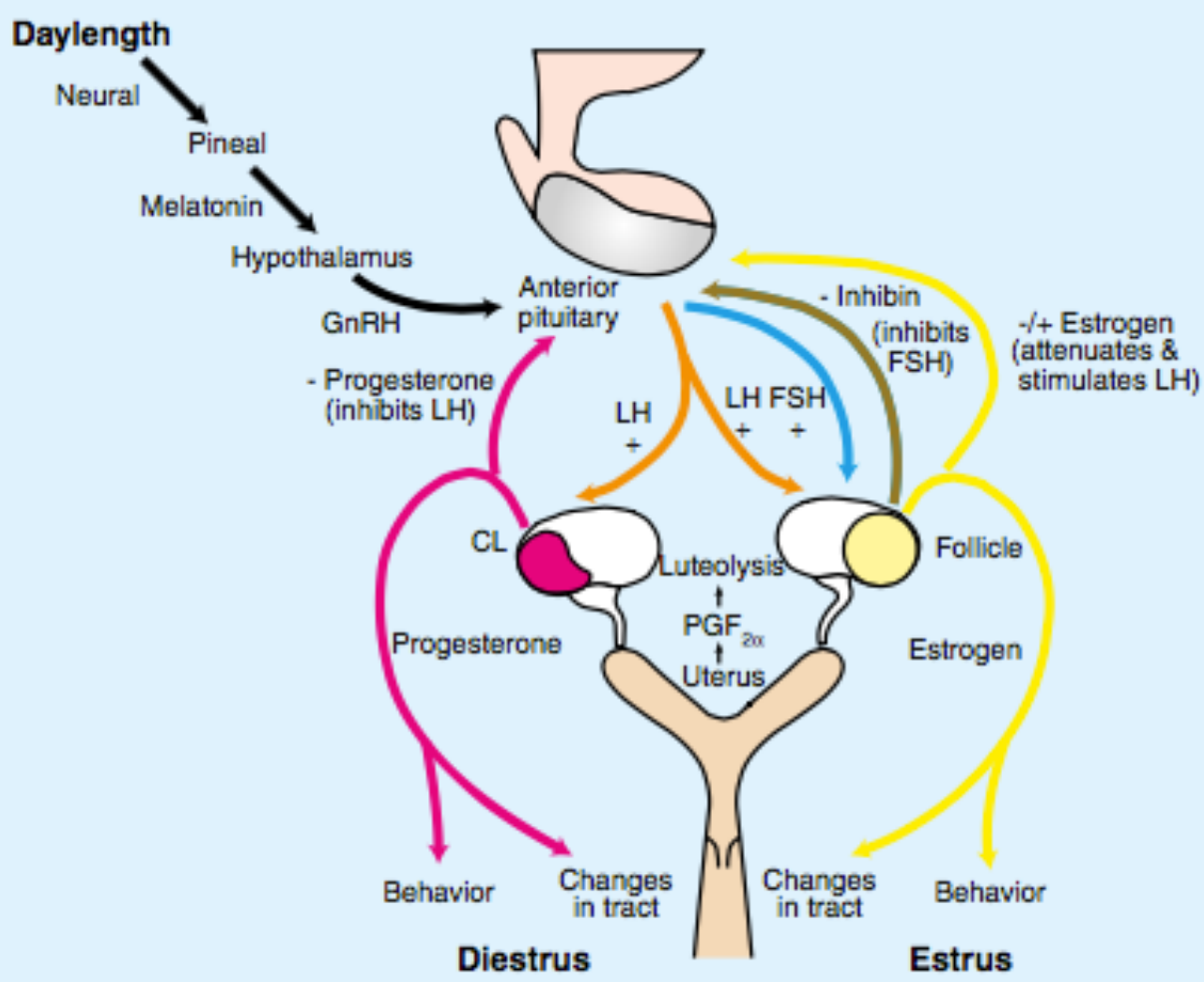

Figure 2. Seasonal influences on the hormonal and behavioral interactions associated with the HPO axis (Samper, 2009). 


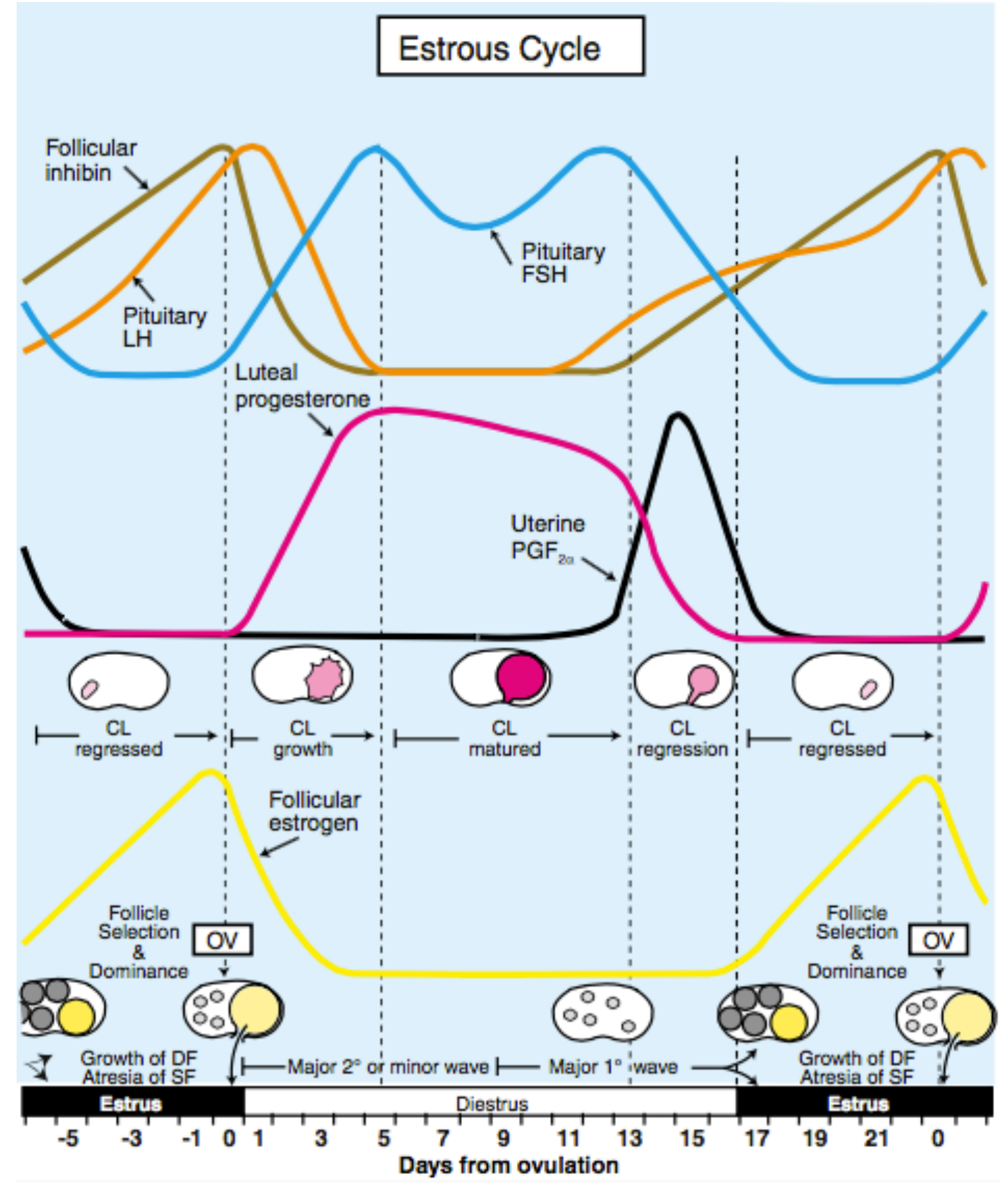

Figure 3. Hormonal profiles and associated ovarian activity during the equine estrous cycle (Samper, 2009) 


\section{Luteolysis}

The phenomenon of luteolysis is also known as the cessation of the luteal phase, or regression of the CL. After day 14 of the mare's cycle, progesterone levels decrease dramatically. This event takes place as a result of the pulsatile release of uterine PGF2 $\alpha$. The combination of the decrease in progesterone and frequent pulses of PGF2 $\alpha$ allows the mechanism of luteolysis to take place. The process of luteolysis is finished by approximately Day 17 of the mare's cycle or when progesterone concentrations are $<2$ $\mathrm{ng} / \mathrm{mL}$ (Samper, 2009). This typically occurs as a result of the absence of an embryonic vesicle that otherwise would block a complex mechanism of events leading to the endometrial secretion of PGF2 $\alpha$ and the subsequent disappearance of the CL (Samper, 2009). From an evolutionary standpoint, luteolysis appears to have evolved as a means to allow mammals to increase their reproductive efficiency. This process allows the animal, if it did not conceive, to have a short period of time (diestrus) where progesterone is secreted, resulting in a reduction of cyclic activity and quiescence of the myometrium. Following this time, the CL is removed via the process of luteolysis, and a new reproductive cycle can begin (McCracken, 1999).

\section{Uterine Role in Luteolysis}

The uterus plays an important role in luteolysis and is responsible for the mechanisms that allow the CL to persist or regress (Ginther, 1990). Regression of the CL occurs as a result of pulsatile secretion of PGF2 $\alpha$ from the endometrium, which also brings about the end of diestrus (Alcantara et al., 2005). As previously mentioned, the decline of progesterone is a hallmark characteristic of luteolysis, as well as the transition 
of the CL into the subsequent structure known as the corpus albicans (McCracken, 1999). The mechanism of luteolysis has been studied in humans, as well as horses and other livestock animals. Interestingly, the process of luteolysis is different for each species, with horses being especially different from other livestock animals. These differences begin with the pulses of PGF2 $\alpha$, which are measured in the blood by detecting amounts of the primary systemic metabolite of PGF2 $\alpha, 13,14$-dihydro-15-keto PGF2 $\alpha$ (PGFM). PGFM is measured in the blood as a result of PGF2 $\alpha$ having a very short half-life, thus making it hard to measure, as opposed to PGFM, which is commonly measured in research settings because it is longer lasting and presents an accurate representation of circulating PGF2 $\alpha$ (Ginther, 2012).

There is a distinct difference in the route of PGF2 $\alpha$ transport between mares and ruminants. The transport of PGF2 $\alpha$ from the uterus to the CL in mares differs due to PGF2 $\alpha$ being transported from the uterus to the ovaries via whole-body (i.e., systemic) circulation, differing from cattle and the local transport and effectiveness of PGF $2 \alpha$ via countercurrent exchange from the utero-ovarian vein to the ovarian artery. This occurs in ruminants as a result of the venous and lymphatic vessels of the uterine horn passing along the ovarian pedicle in close proximity to the ovarian artery. PGF2 $\alpha$, which is fat soluble, passes through the walls of the uterine vessels and the ovarian artery, which are near each other, thus countercurrent exchange and local delivery of PGF2 $\alpha$ to the ovary and CL, is achieved (Ginther et al., 1972).

Mares, differing from ruminants, do not have the proximity of uterine vessels and ovarian artery needed in order to achieve counter current exchange of PGF2 $\alpha$. The ovarian artery lacks major contact with the uterine vein and thus the secretion of PGF2 $\alpha$ 
and action on the CL takes place systemically (Ginther et al., 1972). This phenomenon has been established by various studies, which had the common goal of establishing the systemic route of PGF2 $\alpha$ in the mare. Douglas et al. (1975a) used three different doses of PGF2 $\alpha(0,0.25$, or $1.25 \mathrm{mg})$ and 3 different routes of administration of PGF2 $\alpha$ in order to better understand the luteolytic effect of PGF2 $\alpha$. They found that there was no significant difference between the administrations of PGF $2 \alpha$ locally or systemically. Ginther and First (1971) found that the CL was maintained despite partial hysterectomy and no difference in whether the contralateral or ipsilateral tissue to the CL was removed. Further studies by Ginther included the observation of the unilateral relationship of the embryo and uterus in ruminant animals versus mares. Mares displayed a relationship between uterus and embryo that allowed for the CL to be maintained while the embryo moved to different locations within the uterus. This movement differs from the stationary location of the embryo in ruminants and further solidified that the unilateral utero-ovarian relationship and intrauterine effectiveness of PGF2 $\alpha$ is effective in ruminants, but not mares (Ginther et al., 2009)

\section{Role of oxytocin in luteolysis}

As previously mentioned, in mares, as well as many other domestic animals, PGF $2 \alpha$ is secreted in a pulsatile fashion during luteolysis. PGF2 $\alpha$ is considered to be responsible for luteolysis in equines and induces luteolysis in both the diestrus period and early pregnancy in mares (Douglas and Ginther, 1972). The mechanisms that lead to the secretion of PGF2 $\alpha$ release in mares are not fully understood, however, in domestic ruminants, it is known that the release of PGF2 $\alpha$ from the endometrium is induced by the action of oxytocin, likely from the posterior pituitary, on endometrial oxytocin receptors 
(Silvia et al., 1991). The development of these oxytocin receptors is dependent on the circulating presence of steroid hormones (Vallet et al., 1990). During late diestrus, estrogen interacts with the uterus, which has been primed by progesterone, and increases the amount of oxytocin receptors present (Zhang et al., 1992). The PGF2 $\alpha$ that is secreted as a result of the action of oxytocin from the posterior pituitary then stimulates the secretion of oxytocin from the corpus luteum (Flint and Sheldrick, 1982). This order of events creates a positive feedback loop, which subsequently results in an increased production of PGF2 $\alpha$, creating the characteristic spike in PGF2 $\alpha$ needed for luteolysis. Although it is not fully understood in the equine species, it is thought that oxytocin does play a role in the luteolytic process in mares.

As research has continued on the role of oxytocin in mares, it has become generally accepted that oxytocin plays an important role in the secretion of PGF2 $\alpha$. The origin of oxytocin related to luteolysis in mares is thought to be from the posterior pituitary (Vanderwall et al., 1998) and/or from the endometrium (Stout et al., 2000), but not from the CL (Stevenson et al., 1991). The oxytocin secreted from both sources stimulates the secretion of uterine PGF2 $\alpha$, and additional oxytocin is released in response to PGF2 $\alpha$, thus creating a positive feedback loop. This positive feedback mechanism is thought to be involved in the multiple large pulses of PGF2 $\alpha$ that are observed during luteolysis (Stout, 2011).

It has been found that each pulse of PGF $2 \alpha$ during luteolysis is also associated with a pulse of oxytocin, which supports the general consensus that oxytocin plays a key role in equine luteolysis (Ginther and Beg, 2009). Other studies that have contributed to the theory include examples such as Betteridge et al. (1985) who found that oxytocin 
administered during late diestrus results in a rapid increase of plasma PGFM, as well as a study by Goff et al., (1987) which established that PGFM levels in response to oxytocin reach a maximum near the time of luteolysis. Subsequent studies demonstrated that the late diestrus increase in oxytocin responsiveness correlated with an increase in the binding capacity of endometrial oxytocin receptors (Starbuck et al., 1998; Sharp et al., 1997).

In nonpregnant mares, there is a corresponding rise in the ability of the endometrium to secrete PGF2 $\alpha$ in response to oxytocin, and an increase in the concentration of oxytocin receptors at the end of diestrus (Starbuck et al., 1998). Both are high between days $10-15$ post ovulation, however, in contrast to this phenomenon, prior to day 10, the concentration of endometrial oxytocin receptors and enzymes necessary for the synthesis of PGF2 $\alpha$ are low. The low concentration of receptors effectively interrupts the ability of enough oxytocin to bind and stimulate PGF2 $\alpha$ secretion (Boerboom et al., 2004).

The development of oxytocin receptors and the ability of the endometrium to then release PGF2 $\alpha$ in response to oxytocin is the first key aspect of luteolysis in the mare. The second important aspect of luteolysis is the upregulation of enzymes that play a role in the synthesis of PGF2 $\alpha$ (Boerboom et al., 2004). Prostaglandins are produced in response to a wide variety of stimuli, including oxytocin binding to its receptor, which ultimately results in the activation of phospholipase $A_{2}\left(\mathbf{P L A} \mathbf{A}_{2}\right)$ that results in the liberation of arachidonic acid (AA) from membrane phospholipids (Boerboom et al., 2004). This phenomenon generates the substrate necessary for PGF2 $\alpha$ synthesis (Keith et al., 2013). 
Oxytocin receptor activation also plays a role in the activation of mitogenactivated protein kinase, which is important in the regulation of cyclooxygenase gene expression (Molnar et al., 1999; Soloff et al., 2000). These cyclooxygenase enzymes are rate-limiting enzymes for prostaglandin synthesis and occur in two forms. Cyclooxygenase 1 (COX-1) and cyclooxygenase-2 (COX-2) both work downstream of PLA 2 and convert arachidonic acid to prostaglandin $\mathrm{G}_{2}$ and $\mathrm{H}_{2}$. Prostaglandin $\mathrm{H}_{2}$ can then be converted into PGF2 $\alpha$ by prostaglandin F synthase (PGFS) in the uterus (Keith et al., 2013).

COX-2 appears to be more heavily involved in the mechanisms of luteolysis and maternal recognition of pregnancy than COX-1. In both cows and sheep, COX-2 expression was found in late diestrus, occurring around the time of luteolysis, however, COX-1 was minimally found in sheep and undetectable in cows (Charpigny et al., 1997; Arosh et al., 2002) While COX-2 is strongly expressed around the time of luteolysis, this phenomenon does not occur during pregnancy in the mare. This suggests that the equine conceptus somehow blocks the synthesis of PGF2 $\alpha$ in the endometrium by repressing COX-2 expression. It appears that the prevention of luteolysis depends on the inhibition of COX-2 expression and the decrease of oxytocin receptors (Boerboom et al., 2004).

Understanding the complex role of oxytocin in equine luteolysis and pregnancy is important for the use of oxytocin in preventing luteolysis. Preventing the termination of the CL through understanding the interactions of oxytocin is key for the use of oxytocin as a route to prolong CL function in mares. 


\section{Prolonged Luteal Function}

The condition of prolonged luteal function can occur spontaneously in the mare, creating a difficult challenge in mare reproduction. As previously reviewed, the luteolytic event is characterized by the structural and functional demise of the CL. At times, and for many reasons, the CL can spontaneously remain present on the ovary beyond the expected time of luteolysis in a nonpregnant mare. This occurrence is referred to by many different terms, but all are similar in referring to persistence of the CL on the ovary.

Prolonged, or persistent luteal activity can occur in mares during approximately 8$10 \%$ of interovulatory intervals during peak ovulatory season. This number increases significantly during the fall transition period, rising to $25 \%$ (King et al., 2010). The occurrence of persistent luteal function has been associated with a few different uterine pathologies such as pyometra, as well as with early embryonic loss (Hughes et al., 1979; Bergfelt et al., 1992). There are instances where the CL is prolonged or persistent without any obvious reason and, in that situation, is typically referred to as spontaneous or idiopathic prolonged CL function (Stabenfeldt et al., 1974; Ginther, 1990).

There are a few situations that are thought to be the source of spontaneously prolonged CL function including the failure of the CL to respond to PGF2 $\alpha$, failure of the PGF2 $\alpha$ to travel to the CL, and failure of the uterus to synthesize PGF2 $\alpha$ (Ginther, 1990). Mares are thought to have prolonged CL function when their progesterone concentrations are greater than $1.0 \mathrm{ng} / \mathrm{mL}$ for at approximately 60 days, although the duration can range from 35-95 days (Santos et al., 2015). 
While the development of spontaneously prolonged CL function can be inconvenient and frustrating in equine reproductive biology, it does also serve as a basis of understanding for prolonging CL function intentionally for the purpose of estrus suppression. This method would be an effort to use the CL and subsequent progesterone levels to keep the mare out of normal estrus, and allow the naturally secreted progesterone to eliminate behaviors associated with estrus. Prolonging CL function is an excellent option for estrus suppression in equine performance settings and will be discussed in detail later in this review.

\section{General Methods of Estrus Suppression}

Prolonging CL function is not the only method of estrus suppression that is used within the equine industry. For the purpose of this review, multiple other methods will be outlined in order to give an overview of the advantages and disadvantages of each.

Previously in this review, the issue of mare performance and behaviors related to the estrous cycle was addressed. The common complaint of those involved in the industry has been a factor in the research efforts for estrus suppression. For years, different methods have been used with varying levels of success. Mares are used often in the performance industry and the control of their estrous cycles and subsequent behaviors is warranted. As stated previously, the effect of the estrous cycle, particularly during the state of estrus, on the performance of mares can be variable, making the showing and use of these animals difficult or inconvenient.

Over the years, the development of different methods of suppressing estrus has grown and there are many different avenues to achieve the desired effects. Some 
methods are more effective than others and have led to some techniques being less frequently used and other, newer techniques developing. Overall, there is a growing need for the effective control of estrus that will benefit the equine performance industry. Much research has been dedicated to this topic and it is the purpose of this review to outline and describe the various methods that are available to suppress estrus in addition to their effectiveness and safety.

The methods of estrus suppression that exist can be broken down into a few different categories. Most of these methods fall under the categories of hormonal, surgical, immunologic, and others methods. It is important to note that mares are unique animals, differing in many ways from other domestic animals. Previously, this review has pointed out differences in anatomy and physiology that vary greatly from other domestic species pertaining to reproduction. Some methods of synchronization or suppression of estrus used in other species are not necessarily effective in the equine species. The following methods to be reviewed represent the general body of research and methods related to estrus suppression in mares.

\section{Hormonal Methods and Methods of Prolonging Function of the CL}

\section{Progesterone}

The use of exogenous progesterone/progestins has been widely used as a method of estrus suppression. Staring in the 1960s, Loy et al., (1966) found that intramuscular injection of $0.2 \mathrm{mg} / \mathrm{kg}$ of progesterone oil was effective in suppressing signs of estrus in mares (Loy and Swan, 1966). Although this was found to be effective and progesterone in oil is available from pharmacies, it's need for daily administration and long-term 
injections proved limiting. Progesterone has historically been associated with tissue reactions at the injection site, making this method undesirable to owners and creating horses with needle aversions (Pryor and Tibary, 2005). One alternative that developed was the use of another compounded formulation of progesterone, this time a long-acting formulation of 1.5 grams $(\mathrm{g})$, which maintained blood progesterone levels above 1.0 $\mathrm{ng} / \mathrm{mL}$ for approximately 10 days (Vanderwall et al., 2007a). Although this compounded formula allowed for more time between injections, the potential for soreness at the injection site was again a limitation for use in performance horses. The long-acting formulation is also not approved by the FDA, which poses risk to veterinarians and clients.

Perhaps the most commonly used and successful method of administration of exogenous progesterone/progestins is altrenogest, an orally active synthetic progestin. It is FDA approved, and considered the "gold standard" as far as methods used to suppress estrus in mares. The typical dose is $0.044 \mathrm{mg} / \mathrm{kg}$ daily, orally and has been proven to be effective in suppressing estrus. The altrenogest is most widely known as ReguMate (Intervet/Merck Animal Health, Summit, NJ), and while it is proven to be effective, one study found that $76.6 \%$ of veterinarians participated in administering altrenogest to performance mares with an observed decline in performance related to estrus, but only $44 \%$ of owners reported it to be successful (80\% improvement) (Jorgensen et al., 1996). This can be related to the ability of mares to maintain follicular activity and possible ovulation. As a result, mares that display preovulatory pain related to follicles and ovulation may show continued discomfort despite treatment with altrenogest. Other disadvantages exist such as the need for daily administration, expense, and the added 
safety concern of personnel during handling and administration (Squires et al., 1979; Vanderwall, 2012). Alternatively, it has been reported that IM administration of altrenogest in a compounded formula containing $225 \mathrm{mg}$ or $450 \mathrm{mg}$ of altrenogest with a sustained-release administration effectively blocked estrous behavior for 12 and 15 days, respectively. Administration of the $500 \mathrm{mg}$ of altrenogest suppressed estrous behavior for approximately 30 days (Storer et al., 2009). Although injectable altrenogest appears effective, it is not an FDA approved method and the compounded products can vary in potency and stability. This poses difficulties with variable results as well as a problem for veterinarians who should use FDA approved products (Vanderwall, 2013). In addition to these disadvantages, another issue exists. Altrenogest is a $17 \alpha$-allyl derivative of trenbolone, an anabolic steroid similar to testosterone. Because of the similarities to anabolic steroids, the use of altrenogest in performance horses is under increased scrutiny and is considered a doping agent in some countries (Pryor and Tibary, 2005). However, one study showed that mares treated with altrenogest for the recommended period of eight weeks did not display any characteristics of anabolic steroids in horses such as dominance, body mass, or body condition scores compared to control mares (Hodgson et al., 2005). Other restrictions related to the administration of altrenogest also exist. Longacting progesterone is not permitted by the British Jockey club, the Swedish Trotting Association, and the International Federation for Equine Sports. In addition to these restrictions, the use of oral altrenogest is also prohibited for competition horses (Hedberg et al., 2006).

There have been reports of the use of other synthetic progestins for estrus suppression in mares, however, none have been found to stand up to rigorous testing and 
still be deemed effective (Vanderwall et al., 2012b). Reportedly, other synthetic progestins are rather ineffective, so altrenogest remains the most widely used and successful method of administering exogenous progesterone/progestins, however because of the many drawbacks, an effective alternative is needed.

\section{Pregnancy}

Pregnancy is another means of estrus suppression that has been found to be effective. This takes advantage of the natural role of the conceptus to effectively block luteolysis, subsequently maintaining CL function and continuing secretion of progesterone. In a study by Lefranc and Allen, the establishment of pregnancy, followed by the manual transrectal rupture of the conceptus between days 16 and 22 of gestation resulted in 10 of 11 mares (91\%) displaying prolonged CL function for at least 60 days. These mares did not display estrous behavior during that time (Lefranc and Allen, 2004). A pregnant mare can also be aborted between days 50-60 of gestation and have elevated progesterone levels for 120 days or more. This is much more difficult than aborting the fetus at an earlier time. Aborting later, during those particular days of the pregnancy is effective as a result of the endometrial cups that have developed by that period and the mare will not return to estrus for approximately 60 days. It is important to note that a small amount of mares will also display behavioral signs during pregnancy (Nie, 2007). While pregnancy is an effective method of suspending cyclicity, there are some obvious disadvantages that may prove undesirable for many horse owners. Factors such as the cost involved with establishing pregnancy, especially if a foal is undesired, and the ethics involved with terminating a healthy conceptus may be unacceptable to horse owners (Vanderwall, 2013). 


\section{Implants}

A variety of implants containing progestins, which are labeled for use in other species, have been used experimentally in mares in an effort to suppress estrus.

Progesterone delivered vaginally through the use of a Controlled Intravaginal Drug Release (CIDR) has also been used, however, it was not considered to be a useful method in performance horses (Pryor and Tibary, 2005).

The use of bovine hormonal implants has also been examined for use in mares. In cattle, the implants are used as weight gain promoters. These implants come in various forms such as Synovex-C $₫($ Fort Dodge Animal Health, Overland Park, KS) which contains $100 \mathrm{mg}$ of progesterone and $10 \mathrm{mg}$ of estradiol benzoate, or Synovex-S ${ }^{\circledR}$, (containing $200 \mathrm{mg}$ of progesterone and $20 \mathrm{mg}$ of estradiol benzoate). The use of these implants has been frequently talked about and used in equine medicine, and in 1996, a survey reported that the use of these implants were the second most commonly used method for estrus suppression. Almost $71 \%$ of owners and trainers felt that it was effective, however, the scientific data shows that the use of these implants is not effective in suppressing estrus in mares (Jorgensen et al., 1996). The doses of these implants have even been used in large numbers (up to 80 implants) rather than the labeled dose of eight pellets. The pellets have been implanted in various regions of the mare's body including the pectoral region, under the mane, and in the vulva. Scar tissue and inflammation can develop at these sites (Nie, 2007). The unsuccessful nature of using these implants is due to the lack of absorption of progesterone in sufficient quantity (McCue et al., 1997).

Other implants have been studied, such as an implantable norgestomet (Crestar, Intervet Australia, Bendigo East Victoria, Australia), a pellet that is marketed for estrus 
suppression in mares, and Levonorgestrel (Norplant, Wyeth, Collegeville, PA), which is an implantable progestin used as a contraceptive in women. There is la lack of evidence of valid information regarding dose, frequency, response, or safety of these products. Another implant that has been examined is Zeranol (Ralgro, Schering-Plough, Kenilworth, NJ), which is an anabolic agent used for growth stimulation in cattle. Veterinarians report minimal use for estrus suppression in mares and those that have administered it used doses ranging from 1-3 pellets (12-36 mg) per mare. All reports available indicate that Zeranol is ineffective for estrus suppression in mares (Nie, 2007).

The use of deslorelin acetate in the form of an implant known as Ovuplant (Fort Dodge) has also been used. Deslorelin Acetate is an analogue of GnRH and has been found to induce ovulation in mares when a follicle of greater than $35 \mathrm{~mm}$ in diameter is present (McKinnon et al., 1993; Mumford et al., 1995). One study showed that upon implanting a double dose (two 2.1 Ovuplant implants) of deslorelin acetate, most mares displayed suppressed follicular activity for at least 30 days (McCue et al., 2000). In order to achieve complete arrest of ovarian activity, Johnson et al., reported that three deslorelin implants were used, however, these results were not completely reliable. When mares received three implants, the interovulatory period was extended (36.8 days) as compared to mares with a single implant (22 days). While it is possible that some mares are sensitive to down regulation, complete ovarian inactivity was not achieved, even with three implants (Johnson et al., 2002; Johnson et al., 2003).

It appears that the use of various implants is useful in some situations, with different products being more successful than others. The need for a method of estrus suppression that is safe, as well as reliable is still needed. 


\section{Glucocorticoids}

There appears to be conflicting reports regarding the effectiveness of glucocorticoids on suppressing estrus in mares. One group reported that administration of dexamethasone (30 mg/day) to mares that are on day 10 of the cycle (post-ovulation) suppressed estrus in seven of eight mares compared to control mares (Asa and Ginther, 1982). The controversy lies in the contrasting report of McKinnon et al., (1997) who were unable to suppress or prevent follicular development of the estrous cycle when administering dexamethasome in late estrus. Although there are reports of effective use of dexamethasone, it is thought that there are potential effects of long-term use that warrant caution. Veterinarians surveyed reported no use of glucocorticoids to suppress estrus (Nie, 2007).

\section{Medroxyprogesterone Acetate}

The use of other progestins has been examined such as megestrol acetate, hydroxyprogesterone caproate, and hydroxyprogesterone hexanoate. These progestins failed to be useful to help maintain pregnancy in the mare, most likely because of the inability to bind to the progesterone receptor in horses. One long-acting progestin that has also been examined for equine use is medroxyprogesterone acetate (MPA) better known in human medicine as Depo-Provera (Pfizer). It is highly successful as a human contraceptive given every 3 months via injection. It has been found to be effective in suppressing estrus in queens and bitches, however, it is associated with a high rate of undesirable side effects (Kutzler and Wood, 2006). The use of MPA in mares has occurred, but results and effectiveness vary. Gee et al., (2009) found that administration 
of compounded MPA starting on day 7 with 1,600 mg MPA intramuscularly and continuing with $400 \mathrm{mg}$ on days 14, 21, 28, 35, and 42 had no effect on estrous behavior, nor follicular development, serum progesterone or LH concentrations.

\section{Induction of a Late-Diestrus Ovulation}

Mares, as mentioned earlier, have several differences from females of others species in various ways. One such difference unique to mares is the ability to ovulate during diestrus, despite high progesterone concentrations. This phenomenon can happen in approximately $20 \%$ of Thoroughbreds and Quarter Horses during the luteal phase, however, in ponies, the frequency is very low (Wesson and Ginther, 1981; Hughes et al., 1985). Spontaneous diestrus ovulations can occur between one to four days prior to luteolysis and may cause a prolonged luteal phase. This is due to the immature CL being refractory to prostaglandin (Douglas and Ginther, 1975b). Inducing a late-diestrus ovulation using human chorionic gonadotropin (hCG) has been explored. Hedberg et al. (2006) conducted a study during which five treatment mares and four control mares were monitored starting on day 8 post-ovulation. Using transrectal palpation and ultrasound, mares were examined until a diestrus follicle greater than $30 \mathrm{~mm}$ was found. Treatment of saline or 3000 units of hCG intramuscularly followed. The mares continued to be monitored and at the conclusion of the study, three of the four mares that developed a 30 $\mathrm{mm}$ follicle and received hCG treatment, ovulated and displayed prolonged luteal phases lasting 58 to 82 days after treatment.

This method appears successful, however, it is important to note that one mare never developed a large enough follicle to be treated with hCG. Also, of the mares that were treated, five of the nine required multiple estrous cycles to develop a follicle large 
enough to be treated (Hedberg et al., 2006). The advantages of this method are outweighed by the cost and effort made to frequently check the mares to determine eligibility for treatment, as well as the fact that some mares may take multiple cycles to develop a suitable follicle or one at all. This does not provide owners with a method that allows for estrus suppression in a timely manner and further exploration for a safe, reliable, and effective method are needed.

\section{Intrauterine Infusion of Plant Oils}

Intrauterine infusion of plant oils as a method of suppressing estrus is another avenue that has been explored. A study was published by Wilsher and Allen (2011), demonstrating that infusion of $10 \mathrm{mg}$ of estradiol in $1 \mathrm{~mL}$ of fractionated coconut oil was effective. Administration on day $6,8,10,12$, or 14 post-ovulation resulted in prolonged CL function in $25 \%, 75 \%, 92 \%, 83 \%$, and $50 \%$ of treated mares, respectively. Further investigation demonstrated that estradiol was not needed for prolonged CL function because $1 \mathrm{~mL}$ fractionated coconut or peanut oil, neither with estradiol, on day 10 resulted in $92 \%$ of mares displaying prolonged CL function. It has been hypothesized that the effectiveness of infusion of plant oils is based on the fatty acid milieus present in the oils of both plants and the role of modulating synthesis and/or secretion of PGF2 $\alpha$ near the time of luteolysis, thus resulting in prolonged CL function. The infusion of plant oils appears to be an effective method of suppressing estrus, however, more research on the topic is needed in an effort to establish safety and long-term effects. 


\section{Intrauterine Device}

Placement of an intrauterine device to prolong function of the CL is a common method of estrus suppression. Nie et al., (2003) found that placement of a 25 or $35 \mathrm{~mm}$ glass ball into the uterus, at the time of ovulation, prolonged CL function in seven of 18 mares (39\%) that retained the glass ball. Six of 12 mares quickly expelled the $25 \mathrm{~mm}$ glass ball after insertion. In the mares that developed prolonged CL function for approximately 90 days, blood progesterone levels did not decline below $1.0 \mathrm{ng} / \mathrm{mL}$ and no estrous behavior was exhibited. In the control group, four of 32 mares (13\%) displayed spontaneously prolonged luteal function, a phenomenon that has been discussed previously.

This method appears effective in blocking estrus for an extended time, however in 11 mares that retained the glass ball, extended CL function never developed and the mares continued to cycle normally. In addition, three of the seven mares that received a glass ball underwent two or three normal estrous cycles prior to displaying prolonged CL function. Although the use of a glass ball does work, it's lack of consistency creates a low rate of success. On a "per cycle" basis, the proportion of mares with prolonged CL function was only $7 / 62$ cycles $(11 \%)$ compared to the mares in the control group with spontaneously prolonged CL function, which was 4/50 cycles (8\%) (Nie et al., 2003), which was not significantly different.

It is plausible the mechanism by which a glass ball facilitates prolonged CL function is similar to the action of an embryo to prevent luteolysis. The "embryo mimicking" effect of the presence of the glass ball may interrupt the up-regulation of endometrial gene expression of the enzyme $\mathrm{COX}-2$, which as discussed previously, plays 
an important role in the synthesis and secretion of PGF2 $\alpha$ (Boerboom et al., 2004). In a study by Rivera del Alamo et al., (2008) the use of an intrauterine device induced prolonged CL function in $75 \%$ of the mares in the study. The higher success rate is could be attributed to the fact that no uterine treatments were performed after the insertion of the device, as opposed to Nie et al. (2003) who infused the uterus with $1 \mathrm{~g}$ of ticarcillin disodium in a 35-mL volume, and the fact that Rivera del Alamo, as opposed to Nie, did not use cloprostenol, which can decrease progesterone levels. Other differences in the studies related to the size, material, and weight of the devices. The glass balls used by Nie et al. (2003) had diameters of 25 to $35 \mathrm{~mm}$, making them larger and heavier than the plastic balls used by Rivera del Alamo et al. which were water filled polypropylene balls measuring $20 \mathrm{~mm}$ in diameter. It was hypothesized that a lighter device might move within the uterus more and be more effective in inducing prolonged luteal function, however, there was no significant difference in mobility found. It was concluded, similar to Nie et al., that the "embryo-mimicking" effect of the intrauterine device prevents the upregulation of COX-2 (Rivera del Alamo et al., 2008).

A veterinarian must perform the placement and removal of an intrauterine glass ball. The glass ball is autoclaved for sterilization prior to placement. The mare must be in late estrus or close to ovulation, with a relaxed cervix for the glass ball to be manually placed in the uterus by the veterinarian in sterile procedure. The marble is placed vaginally and pushed through the cervix, followed by location of the glass ball per rectum and pushed forward into the uterine body. Removal involves the mare to be in peak estrus, and the glass ball is manipulated toward the cervix then removed (Nie, 2007). 
In the same study by Nie et al., (2003) the use of intrauterine glass balls was deemed safe. In more recent years, it has been reported that spontaneous fragmentation as well as irritation, colic, and pyometra has occurred (Klabnick-Bradford, 2013; Freeman, 2015). Plastic has been used in an effort to reduce this complication, however, regardless of material used, some mares retain the devices long enough that the presence of an intrauterine device may not be disclosed when the mare is sold, and anecdotal reports of mares becoming pregnant regardless of the device and aborting is also a concern (Vanderwall, 2013).

Because of the variability in effectiveness and the potential for serious complications, a method with increased reliability and safety, as well as easily reversed is needed.

\section{Immunologic}

\section{GnRH vaccine}

As previously reviewed, GnRH plays a pivotal role in equine reproduction. Ovarian activity is heavily influenced by gonadotropin secretion, which is regulated by GnRH. The immunization of horses against GnRH has been researched for several years and numerous studies have taken place to determine the effectiveness of this method. Vaccination against GnRH results in the induction of anti-GnRH antibody and these antibodies bind to endogenous $\mathrm{GnRH}$ preventing it from stimulating gonadotropin secretion from the anterior pituitary gland. The binding in this location prevents the stimulus to gonadotropin secretion and decreases ovarian activity (Pryor and Tibary, 
2005). The use of a GnRH vaccine has been studied in multiple species, from elephants to humans, with a wide variety of objectives.

The use of the vaccine in wild animals has been shown to be an effective method of population control (D'Occhio, 1993; Fayrer-Hosken et al., 2000). Applications for human use includes GnRH vaccine to decrease testosterone levels for treatment of prostate cancer (Simms et al., 2000). Aside from these uses, the application of the vaccine in farm animals is the most relevant to this review. It has been shown to be an alternative to surgical castration and is efficacious in decreasing sexual and aggressive behavior in cattle, as well as the prevention of pregnancy in pigs (Esbenshade and Britt, 1985; Prendiville et al., 1995; Thompson, 2000).

In horses, the use of GnRH vaccine started as an alternative to castration but soon evolved into use in mares. In the first studies, ovarian activity and estrous behavior were not monitored (Garza et al., 1986; Safir et al., 1987). The vaccine was administered with a primary goal of investigating the effects of $\mathrm{GnRH}$ vaccination and the relationship with gonadotropin secretion. At the cessation of the studies, the mares were either ovariectomized or the study was terminated and mares were not tracked for normal cyclicity. Thus, no information was gathered about the safety of the immunization regarding future reproduction. Later studies found the same treatment effective in six 2year-old fillies and data was collected regarding behavior as well. Both ovarian function and estrous behavior were suppressed and the fillies returned to normal reproductive function (Tshewang et al., 1997), however, in mature mares, there was greater variation in these results, with anestrus lasting up to 15 months in two of three mares vaccinated. The study also reported that mares with totally inactive ovaries continued to show estrus 
signs with varied duration and variability (Dalin et al., 2002). This is related to the occurrence of "paradoxical estrus" in mares, which is due to the fact that hormone driven behavior can originate from locations other than the ovaries, such as the adrenal glands. This phenomenon is also a factor in the practice of ovariectomy, which is discussed below.

In a study by Imboden et al. (2006) the primary goal was to investigate the results of immunization of GnRH and effects on the reproductive tract. The mares were administered Improvac ${ }^{\circledR}$ (CSL Limited, Australia), which has been successfully used to control boar taint in pigs. All nine treatment mares showed an immediate response to the first vaccine and peak response after the booster injection. Titers reached high levels and then slowly declined until 100 weeks following the first vaccination, however, as demonstrated by previous studies, titer can be independent of degree of ovarian suppression and variable per individual. In spite of suppression of ovarian function, four mares displayed sporadic estrous behavior and one mare continuously displayed those behaviors. In addition to variation in titer, resumption of normal cyclicity was variable and adverse effects such as tissue swelling at the injection site, lameness, and fever were also reported.

More recently, another GnRH vaccine (EquityTM oestrus control: CSL Animal Health, Victoria, Australia) was licensed for use in mares in Australia, specifically for control of estrus. The protocol involves four intramuscular injections of vaccine to the pectoralis region of muscle. The treatments are staggered with the first injection administered 10 days post-ovulation, the second injection 20 following the first, and the third 20 days following that. The fourth injection is administered 30 days after the third 
injection. Immunization resulted in a response of $\mathrm{GnRH}$ antibodies in all mares, however, individual variability in response once again occurred. Also, because the GnRH is mixed with Equimune ${ }^{\circledR}$, which has a strong effect at the injection site, inflammation and irritation can occur (Pryor and Tibary, 2005)

The use of GnRH vaccine is somewhat effective and eventually reversible, however, the length of time needed for resumption of cyclicity does not provide a method that is easily reversible for breeding purposes. The failure of some mares to return to cyclicity is concerning as well. Most importantly, because of the nature of the adrenal glands, merely suppressing ovarian activity does not always prevent unwanted estrous behavior and thus the vaccination against $\mathrm{GnRH}$ does not provide a method that is as predictable or controllable as do other treatments.

\section{Surgical}

\section{Ovariectomy}

Ovariectomy, or "spaying" a mare is considered a last resort for behavioral modification or estrus suppression. This procedure involves the removal of the ovaries through various methods including a ventral abdominal incision or flank laparotomy, laparoscopy, or colpotomy (Ross, 1991; Hooper et al., 1993; Rodgerson et al., 2001). This method is a permanent procedure, thus eliminating any future reproductive potential.

A common misconception regarding ovariectomy is the complete removal of unwanted behavior or that mare's behavior will be similar to her behavior after exogenous hormones (McCue, 2003). Again, mares differ from other animals due to the fact that not all of their hormone driven behavior originates from ovarian derived 
estrogen. Mares can display "paradoxical" estrous behavior even during seasonally anovulatory periods as well as after ovariectomy. This phenomenon occurs as a result of hormone secretion from the adrenal cortex (Asa et al., 1980). This is an important factor to consider when evaluating ovariectomy.

In a study by Jorgensen et al. (1996), they found that ovariectomy was utilized by $44 \%$ of respondents, and $60.5 \%$ of respondents reported an improvement of behavior in $80 \%$ or more of treated mares. Forty-five percent of owners and trainers reported $80 \%$ or better improvement in athletic performance in ovariectomized mares. These results are much better than scientific reports that show $30 \%$ or more of ovariectomized mares continue to display some form of behavioral estrus. It is important to note that low progesterone is all that is needed for a mare to display estrus and estrogen intensifies estrus, but is not always needed. Thus, if a mare's behavioral issues are truly associated with estrus, ovariectomy could have the opposite effect and make the behavior of the mare worse (Pryor and Tibary, 2005).

The best option for determining if ovariectomy should be performed is the observation of behavior during the winter anestrus period when mare's hormone production and ovarian function are very minimal. Observations during this period could allow options to be carefully weighed and the origin of the mare's behavior to be better understood prior to undergoing a permanent procedure.

\section{Oxytocin Treatment}

Thus far, this review has covered many of the general methods of estrus suppression. These have all fallen into the categories of hormonal, surgical, and 
immunological methods. Most of the methods reviewed in the hormonal category are methods used specifically to prolong the function of the CL on the ovary, thus the natural secretion of progesterone occurs, suppressing estrus naturally. The methods already discussed that fall in the category of prolonged CL function include the use of an intrauterine glass ball, pregnancy, infusion of plant oils, and induction of a late diestrus ovulation. The advantages and disadvantages have been discussed, however, there is need for another method of prolonged CL function that is safe, reliable, effective, and easily reversible.

The administration of exogenous oxytocin during the diestrus period is a promising alternative method of blocking luteolysis in order to prolong the function of the CL. As discussed previously, endogenous oxytocin secretion plays an important role in luteolysis, regulating the secretion of PGF2 $\alpha$ from the endometrium during luteolysis in mares (Vanderwall et al., 1998; Shand et al., 2000). Research has discovered that administration of exogenous oxytocin to mares near the time of luteolysis (days 11-15 after ovulation) induces the onset of PGF2 $\alpha$ secretion, however, if oxytocin is administered prior to day 10 post-ovulation, the opposite effect occurs and PGF2 $\alpha$ is not secreted, luteolysis is disrupted, and the CL remains intact for a prolonged period of time (Betteridge et al., 1985; Goff et al., 1987; Starbuck et al., 1998). Further research of oxytocin occurred with the continuous infusion of oxytocin using an osmotic minipump inserted subcutaneously into the mare. The infusion of $5 \mu \mathrm{h} \mathrm{h}^{-1}$ went from days 8-20 postovulation and resulted in prolonged diestrus in four out of five mares versus all four control mares that were administered saline and underwent luteolysis at the expected time. When the infusion via the minipump began on day 10 , prolonged diestrus occurred 
in three out of five mares and in the two mares without prolonged CL function, luteolysis was induced immediately. Luteolysis occurred at the expected time in the four control mares infused with saline (Stout et al., 1999). This method worked, however, the continuous nature of treatment was impractical as a long-term method for the suppression of estrus.

In an effort to avoid continuous infusion, Vanderwall et al. (2007b) conducted a study in which six mares were treated with 60 units $(3 \mathrm{~mL})$ of oxytocin, IM, twice daily on days 7 to 14 after ovulation. Six control mares were administered the same volume of saline. This proved effective; with prolonged CL function being observed through day 30 in all the treated mares whereas all control mares underwent luteolysis by day 16 of their cycle. It was then hypothesized that a once-daily injection of oxytocin would be as effective as the twice-daily protocol. Once-daily injections would greatly simplify the protocol for veterinarians and owners. In a subsequent study by Vanderwall et al., (2012b) the same 60-unit dose of oxytocin was administered twice daily to seven mares and once daily to eight mares. The occurrence of prolonged CL function was five of seven mares (71\%), five of eight mares (63\%) respectively, while one of seven (14\%) of control mares displayed spontaneously prolonged CL function. No difference $(P>0.05)$ was found in the proportion of mares with prolonged CL function between the once daily and twice daily oxytocin treatments. It was concluded that the administration of oxytocin could be reduced from twice to once daily and still remain effective.

In another study, Vanderwall et al. (2012a) again designed a study around the use of oxytocin to suppress estrus. In this particular protocol, the once daily administration of 60 units of oxytocin was given on days 7 to 14 post-ovulation. The objective was to 
monitor duration of CL function and estrous behavior in mares for 90 days after administration. Two of the nine control mares (22\%) had spontaneously prolonged CL function whereas six of the nine oxytocin-treated (67\%) also had prolonged CL function $(P=0.08) . \quad$ The control mares that displayed spontaneous prolonged $\mathrm{CL}$ function had a mean duration of CL function of 78 days. The six treatment mares had a mean duration of CL function of 69 days. The mares in the control group and one of the mares in the treatment group with prolonged CL function did not display estrous behavior during the time their plasma progesterone remained above $1.0 \mathrm{ng} / \mathrm{mL}$. Interestingly, the remaining five treatment mares with prolonged CL function did display weak estrus occasionally during a period of elevated progesterone. It was concluded that the oxytocin treatment works for approximately two months in two thirds of treated mares.

Other groups have tried the oxytocin protocol with altered dose and route of administration, as well as duration of treatment. Gee et al. (2012) reported that five of six mares (83\%) treated with 10 units of oxytocin intravenously (IV) once daily also on days 7-14 displayed prolonged CL function compared to one of the six (17\%) mares treated with 10 units intramuscularly, and two of the (33\%) mares treated with saline intramuscularly. This data combined with the previously discussed data indicates that the dose of 10 units of oxytocin administered intramuscularly does not prolong CL function and the threshold for an intramuscular dose to disrupt luteolysis is between 10 and 60 units of oxytocin. In all of the mares with prolonged CL function, estrous behavior was inhibited, which demonstrates the effectiveness of administration of oxytocin for estrus suppression. Discovering the threshold for intramuscular injections is important for keeping the protocol user friendly for horse owners. 
In a 2013 study by Keith et al., three different durations of oxytocin treatment were examined. Sixty units of oxytocin were administered intramuscularly on day 8 and then the three different durations of treatment $(2,4$, or 6 days). Administration of oxytocin on days 8 to 10,8 to 12 , an 8 to 14 resulted in prolonged CL function in three of seven (43\%), four of seven (57\%), and six of seven (86\%) of mares, respectively. None of the control mares displayed any prolonged luteal function. These results showed that the proportion of mares with prolonged CL function was increased as treatment days increased, thus confirming that the most effective treatment time for oxytocin is from days 8 to 14 , or the expected time of luteolysis.

In one study, the synthetic oxytocin analog known as carbetocin was administered to mares on days 7 to 14 post-ovulation and compared to another group of oxytocin treated mares for the same duration. The oxytocin treated mares were administered 60 units of oxytocin intramuscularly, once daily. The carbetocin treated mares were administered the equivalent dose of $1.19 \mathrm{mg}$ carbetocin intramuscularly, once daily on days 7 to 14 . The administration of oxytocin increased the inter-ovulatory interval $(P<$ $0.01)$ while the carbetocin decreased the inter-ovulatory interval $(P>0.01)$ and essential "short-cycled" the mares. It was concluded that the use of carbetocin in this dose, treatment, and schedule was not effective in prolonging CL function (Bare et al., 2013). Previously in this review, the role of oxytocin in luteolysis was addressed. It is known that the ability of the endometrium to secrete PGF2 $\alpha$ in response to either exogenous or endogenous oxytocin increases between days 10-15 after ovulation. This sensitivity is related to the rise of oxytocin receptors as well as enzymes needed for PGF2 $\alpha$ synthesis. Before day 10, these same receptors and enzymes are low which plays 
a role in the ability of oxytocin to influence PGF2 $\alpha$ secretion. In an effort to understand the mechanism of action of exogenous oxytocin, Vanderwall et al. (2012b) tested the hypothesis that the effectiveness of the administration of oxytocin on days 7 to 14 of the estrous cycle was effective in preventing luteolysis by inhibiting the rise of endometrial oxytocin receptor concentration. It was found that no difference in endometrial oxytocin receptor concentration existed between treatment and control mares, thus further research was needed to determine the actual mechanism of action. In 2013, Keith et al. published a study examining the same hypothesis, however, they were successful in determining why the oxytocin protocol was effective. It was found that oxytocin treatment suppresses PGF2 $\alpha$ secretion by preventing the upregulation of the gene expression of COX-2 in the endometrium, as previously mentioned in this review.

The body of research on the topic of administration of exogenous oxytocin to suppress estrus in mares is convincing and supports the use of 60 units of oxytocin on days 7 or 8 , to 14 post-ovulation and the subsequent disruption of luteolysis. Numerous studies by Vanderwall (2013) have shown the progression of frequency, duration, and mechanism of oxytocin treatments and their effect on prolonging the CL. The administration of exogenous oxytocin and its ability to prolong CL function with the release of progesterone naturally is advantageous to veterinarians, horse owners, and trainers.

The largest disadvantage to the current oxytocin protocol is the need for detection of day 0 or day of ovulation in order to then begin the treatments on day 7 of the mare's cycle. Detecting ovulation must be done by a veterinarian via transrectal palpation and ultrasound. Multiple trips to the veterinarian in order to establish ovulation are usually 
needed, and the costs and effort incurred with such visits can be a disadvantage. In an effort to address this issue, we hypothesized that by extending the duration of oxytocin administration, treatment could be initiated at any point during the estrous cycle (i.e., without knowing the day of ovulation) and still effectively prolong CL function. Therefore, the objective of this study was to determine if treating mares with oxytocin daily for 29 days would result in prolonged CL function.

\title{
MATERIALS AND METHODS
}

\begin{abstract}
Animals
This study was conducted in the Northern Hemisphere under natural photoperiod using 17 Quarter Horse-type mares that were between 2 and 17 years old and weighed 300 to $500 \mathrm{~kg}$. All animal procedures were approved and conducted following the guidelines of the Utah State University Institutional Animal Care and Use Committee (IACUC). The reproductive tract of each mare was examined with transrectal palpation and ultrasound in April and/or May to confirm that spontaneous seasonal ovulatory activity had commenced (i.e., a CL was identified). All of the mares had ovulated by late May. Prior to the study, no reproductive hormones were administered to any of the mares to regulate their cyclical reproductive activity (i.e., they were allowed to cycle spontaneously without hormonal manipulation). After confirming spontaneous ovulatory activity in all of the mares, no further reproductive examinations were performed for the duration of the study period.
\end{abstract}




\section{Experimental Protocol}

Mares were randomly assigned to two groups: 1$)$ saline-treated control $(n=8)$ and 2) oxytocin-treated $(n=9)$. Prior to initiating treatment, $10 \mathrm{cc}$ of jugular blood was collected from each mare three times weekly $(\mathbf{M}, \mathbf{W}, \mathbf{F})$ for three weeks. This was done to determine, based upon blood progesterone concentration, whether any mares had spontaneously prolonged CL function before treatment was initiated (i.e., blood progesterone remaining $>1.0 \mathrm{ng} / \mathrm{mL}$ continuously throughout the pretreatment period). Mares that displayed evidence of spontaneously prolonged CL function during the pretreatment period were removed from the study. At the end of the pretreatment period (day 1), control mares began receiving $3 \mathrm{cc}$ of sterile saline IM once daily and the oxytocin-treated mares began receiving 60 units $(3 \mathrm{cc})$ oxytocin IM, and those treatments were continued through day 29. Starting on day 1, jugular blood samples were collected daily for 7 days, and then three times weekly (M, W, F) for the duration of the study period (day 80). Blood samples were allowed to clot at room temperature, after which the serum was recovered and kept frozen at $-20^{\circ} \mathrm{C}$ until progesterone was measured. Mares were considered to have prolonged CL function if serum progesterone levels remained $>1.0 \mathrm{ng} / \mathrm{mL}$ for at least 30 days during and/or after the treatment period.

\section{Progesterone Assay}

Progesterone was measured using a commercially available kit (Immulite Progesterone, Siemens, Malvern, PA, USA) designed for an enzyme-amplified chemiluminescence assay system (Immulite 1000, Diagnostic Products Corporation, Los 
Angeles, CA, USA) and performed according to the manufacturer's protocol. The intraassay coefficient of variance was $8.6 \%$ and the inter-assay coefficient of variance was $10.2 \%$. The sensitivity of the assay was $0.2 \mathrm{ng} / \mathrm{mL}$; values below the assay sensitivity were assigned a value equal to the sensitivity.

\section{Statistical Analysis}

The proportion of mares in each group with prolonged CL function was compared using Fisher's Exact Test (GraphPad Software, Inc., La Jolla, CA, 92037). A probability of $\mathrm{P}<0.05$ was considered significant. 


\section{RESULTS}

\section{Pre-Treatment Period}

One saline-treated control mare had blood progesterone concentrations that remained above $1.0 \mathrm{ng} / \mathrm{mL}$ continuously throughout the pretreatment period, indicating spontaneously prolonged CL function (prior to initiating treatment). Therefore, that mare was removed from the study, leaving seven mares in the control group. The remaining mares in both treatment groups demonstrated baseline levels of progesterone at least once during the pretreatment period, indicating they had undergone luteolysis during the 3week period before treatments were initiated, which was taken as evidence of normal cyclicity.

\section{Treatment Period}

One of seven control mares (Figure 4) and seven of nine oxytocin-treated mares demonstrated prolonged CL function that was initiated during the 29-day treatment period. The proportion of mares with prolonged CL function was higher in the oxytocintreated group compared to the saline-treated group ( $7 / 9$ vs. $1 / 7$, respectively; $\mathrm{P}<0.05)$. Three of the seven oxytocin-treated mares that developed prolonged CL function initially underwent luteolysis within 3 to 7 days following the start of oxytocin treatment, and then developed prolonged CL function after the subsequent ovulation during the treatment period (Figure 5). In the other four oxytocin-treated mares that developed prolonged CL function, progesterone remained $>1.0 \mathrm{ng} / \mathrm{mL}$ throughout the treatment period and into the post-treatment period (Figure 5). All mares with prolonged CL 
function maintained elevated blood progesterone concentrations through at least day 56 of the study.

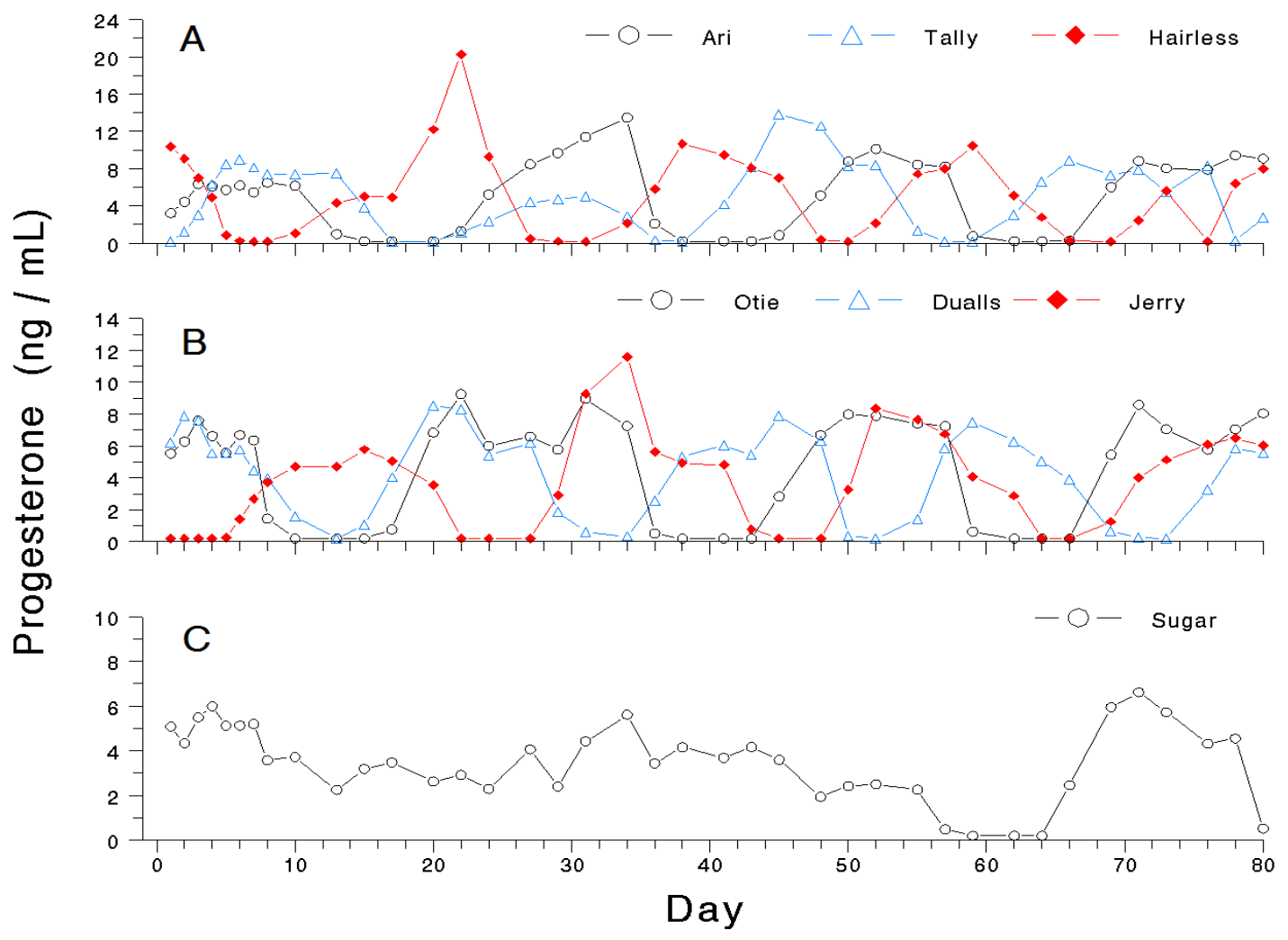

Figure 4. Serum progesterone levels of control mares during and after the treatment period. 


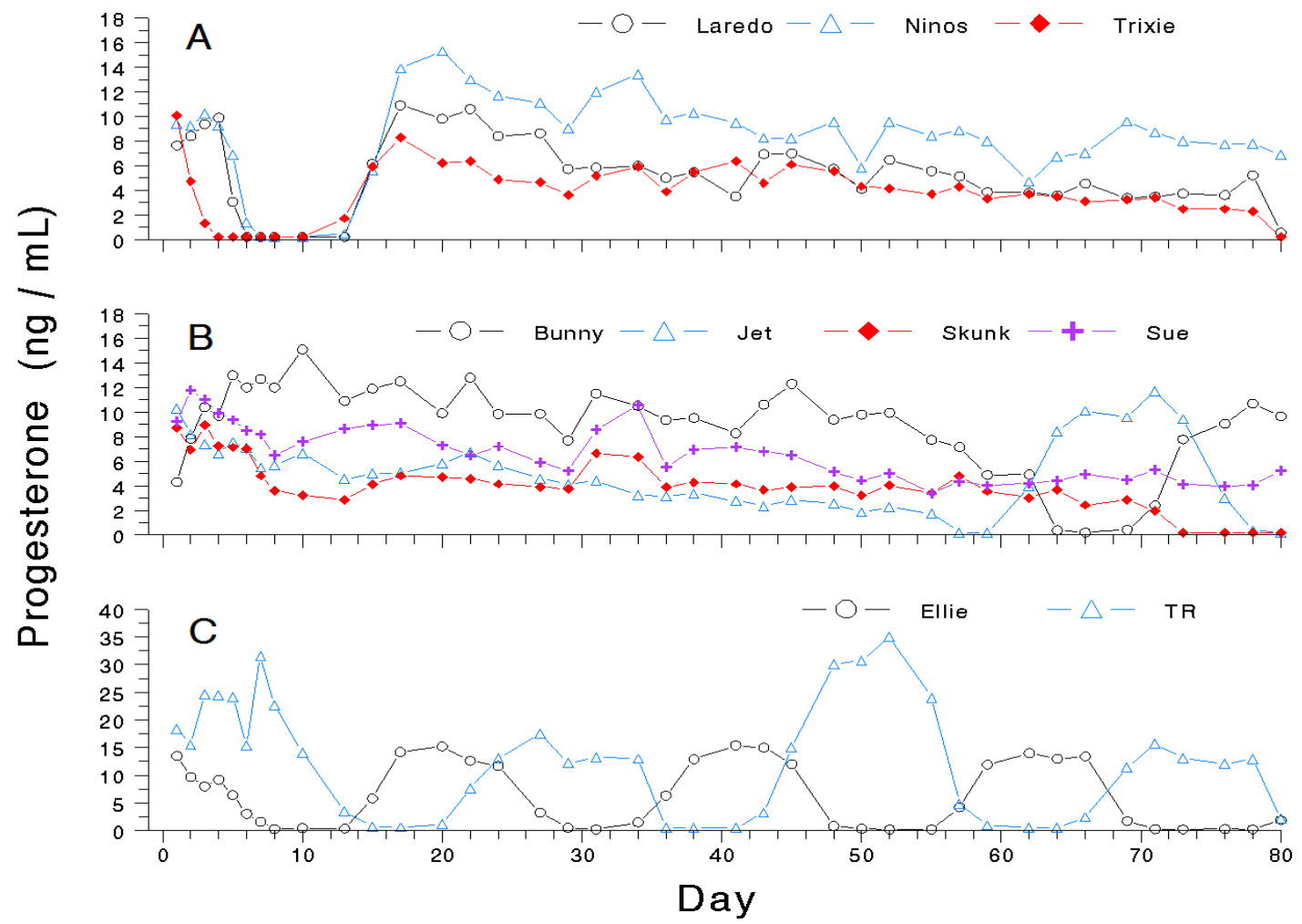

Figure 5. Serum progesterone levels of oxytocin treated mares during and after the treatment period. 


\section{DISCUSSION}

The results of this study supported the hypothesis that extending the duration of oxytocin administration allows treatment to be initiated at any point during the estrous cycle and still effectively prolong CL function. All of the mares with prolonged CL function maintained blood progesterone concentrations above $1.0 \mathrm{ng} / \mathrm{mL}$ for over 50 days, which is a sufficient concentration of progesterone to block estrous behavior (Loy and Swan, 1966; Hawkins et al., 1979). One control mare (14\%) developed spontaneously prolonged CL function (during the treatment period), which has been reported to occur in approximately 8 to $10 \%$ of estrous cycles during the height of the physiological breeding season and up to 20 to $25 \%$ of estrous cycles during the autumnal transition into the anovulatory season (King et al., 2010).

In nonpregnant mares, the ability of the endometrium to secrete PGF2 $\alpha$ in response to oxytocin (endogenous or exogenous) increases between days 10 and 15 postovulation as a result of increasing concentrations of endometrial oxytocin receptors (Sharp et al., 1997; Starbuck et al., 1998) and PGF2 $\alpha_{\alpha}$ synthetic enzymes (Boerboom, et al., 2004). In contrast, before day 10, endometrial oxytocin receptor concentrations and PGF2 $\alpha$ synthetic enzymes are low (Sharp et al., 1997; Starbuck et al., 1998; Boerboom et al., 2004), thus blocking the ability of oxytocin to stimulate PGF2 $\alpha$ secretion. In a previous study by Vanderwall et al. (2012b), it was hypothesized that initiating treatment with oxytocin prior to day 10 post-ovulation prevented subsequent luteolysis by inhibiting an increase in endometrial oxytocin receptor concentration. However, there was no difference in endometrial oxytocin receptor concentrations between control and 
oxytocin-treated mares on day 15 , so that hypothesis was not supported. Subsequently, Keith et al. (2013) demonstrated that initiating oxytocin treatment prior to day 10 suppresses PGF2 $\alpha$ secretion by preventing upregulation of endometrial gene expression of cyclooxygenase-2, the key regulatory enzyme in PGF2 $\alpha$ synthesis/secretion that otherwise would be upregulated on days 14 to 15 , allowing the onset of PGF2 $\alpha$ secretion. Therefore, the anti-luteolytic effect of exogenous oxytocin occurs "downstream" from its receptor.

In an effort to simplify the oxytocin treatment protocol by eliminating the need for detection of ovulation, we extended the treatment period to 29 days and initiated treatment randomly during the estrous cycle. This was done with the anticipation that treatment would likely be initiated in some mares on days 10 to 15 , which as described above, would induce PGF2 $\alpha$ secretion causing luteolysis to occur. Therefore, the 29-day period of treatment was designed to ensure continued treatment of mares in which luteolysis was induced for a long enough period such that after they underwent luteolysis, they would still be receiving oxytocin on the critical days (days 7 to 14) of the following cycle. As these results demonstrated, three of the seven mares that displayed prolonged luteal function initially underwent luteolysis and then subsequently developed prolonged CL function. The other four mares in the treatment group that had prolonged CL function must have received oxytocin treatments beginning prior to day 10 of their cycle, since they did not undergo luteolysis immediately following the start of oxytocin treatment.

In conclusion, the results of this study demonstrated the effectiveness of chronic oxytocin treatment; initiated randomly during the estrous cycle, for prolonging CL function $\mathrm{CL}$ in mares. 


\section{CONCLUSIONS}

The suppression of estrus in mares is a growing trend and is important to the equine industry. Mares are frequently used and the variable behavior and performance related to the estrous cycle is frustrating and costly. Over the course of the last decade, research has developed various methods to suppress estrus and the use of exogenous oxytocin appears to be effective and significant. The 29-day oxytocin protocol addresses issues previously discussed regarding the growing scrutiny of administering synthetic progestins to performance animals and issues with safety for personnel handling hormones. Another advantage of exogenous oxytocin is the easy reversal of the state of prolonged luteal function with a luteolytic dose of PGF2 $\alpha$, which will allow the mare to return to normal cyclicity. The oxytocin protocol is also advantageous because of the low cost of materials, as opposed to synthetic progesterone/progestins. This is of great advantage to the consumer, whereas orally active altrenogest can be expensive and needed long term. The greatest advantage to this protocol exists in the elimination of frequent and expensive trips to a veterinarian. Reducing these trips and the ease of administration of oxytocin in an IM dose presents a method to a consumer that is safe, effective, and inexpensive. Disadvantages do occur, however, and the multiple injections can be difficult with mares that have an aversion to needles, though most of the mares in the study tolerated needles well. Mares are frequently used in the performance industry and much time, training, and expense is invested in these animals. Suppressing estrus using exogenous oxytocin is an effective and desirable method that will allow horse 
owners, trainers, and veterinarians to be successful in the showing and use of these animals. 


\section{REFERENCES}

Alcantara, B., M. Boeta, and A. Porras. 2005. Luteolysis, estrus induction, and clinical side in mares treated with a PDF2 alpha analog, cloprostenol (Sinocrel 11-21). J. Equine. Vet. Sci. 25: 384-386.

Arosh, J. A., J. Parent, P. Chapdelaine, J. Sirois, and M. A. Fortier. 2002. Expression of cyclooxygenases 1 and 2 and prostaglandin e synthase in bovine endometrial tissue during the estrous cycle. Biol. Reprod. 67: 161-169.

Asa, C. S. 1986. Sexual behavior of mares. Vet. Clin. North. Am. Equine Pract. 2: 519534.

Asa, C. S., and O. J. Ginther. 1982. Glucocorticoid suppression of oestrus, follicles, LH and ovulation in the mare. J. Reprod. Fertil. Suppl. 32: 247-251.

Asa, C. S., D. A. Goldfoot, M. C. Garcia, and O. J. Ginther. 1980. Sexual behavior in ovariectomized and seasonally anovulatory pony mares (Equus caballus). Horm. Behav. 14: 46-54.

Bare, C. A., A. R. Schramme, and C. S. Bailey, et al. 2013. The effect of oxytocin or carbetocin administration during mid-diestrus on the inter-ovulatory interval and estrous behavior of mares. Clin. Therio. 5: 27-35.

Bergfelt, D. R., and G. P. Adams. 2007. Ovulation and corpus luteum development. In: J. C. Samper, J. F. Pycock, A. O. McKinnon, editors, Current therapy in equine reproduction. W.B. Saunders, Saint Louis, MO. p 1-13.

Bergfelt, D. R., J. A. Woods, and O. J. Ginther. 1992. Role of the embryonic vesicle and progesterone in embryonic loss in mares. J. Reprod. Fertil. 95: 339-347. 
Betteridge, K. J., A. Renard, and A. K. Goff. 1985. Uterine prostaglandin release relative to embryo collection, transfer procedures and maintenance of the corpus luteum. Equine Vet. J. Suppl. 3: 25-33.

Boerboom, D. et al. 2004. Expression of key prostaglandin synthases in equine endometrium during late diestrus and early pregnancy. Biol. Reprod. 70: 391-399.

Charpigny, G. et al. 1997. Expression of cyclooxygenase-1 and -2 in ovine endometrium during the estrous cycle and early pregnancy. Endocrinology. 138: 2163-2171.

Cox, J. H., and R. M. DeBowes. 1987. Colic-like discomfort associated with ovulation in two mares. J. Am. Vet. Med. Assoc. 191: 1451-1452.

Cummings, J. N. 1942. A study of estrus and ovulation in the mare. J. Anim. Sci. 1: 309313.

D'Occhio, M. 1993. Immunological suppression of reproductive functions in male and female mammals. Anim. Reprod. Sci. 33: 345-372.

Dalin, A. M., O. Andresen, and L. Malmgren. 2002. Immunization against gnRH in mature mares: antibody titres, ovarian function, hormonal levels and oestrous behaviour. J. Vet. Med. A. Physiol. Pathol. Clin. Med. 49: 125-131.

Douglas, R. H., and O. J. Ginther. 1972. Effect of prostaglandin F2a on length of diestrus in mares. Prostaglandins. 2: 265-268.

Douglas, R. H., and O. Ginther. 1975a. Route of prostagland in F2 $\alpha$ injection and luteolysis in mares. Exp. Biol. Medicine. 148: 263-269.

Douglas, R. H., and O. J. Ginther. 1975b. Effects of prostaglandin F2alpha on estrous cycle or corpus luteum in mares and gilts. J. Anim. Sci. 40: 518-522. 
Esbenshade, K. L., and J. H. Britt. 1985. Active immunization of gilts against gonadotropin-releasing hormone: effects on secretion of gonadotropins, reproductive function, and responses to agonists of gonadotropin-releasing hormone. Biol. Reprod. 33: 569-577.

Fayrer-Hosken, R., D. Grobler, J. Van Altena, H. Bertschinger, and J. Kirkpatrick. 2000. Immunocontraception of african elephants. Nature. 407: 149.

Flint, A. P., and E. L. Sheldrick. 1982. Ovarian secretion of oxytocin is stimulated by prostaglandin. Nature. 297: 587-588.

Freeman, C., and S. Lyle. 2015. Chronic intermittent colic in a mare attributed to uterine marbles. Equine. Vet. Educ. 27: 469-473.

Garza, F., Jr. et al. 1986. Active immunization of intact mares against gonadotropinreleasing hormone: differential effects on secretion of luteinizing hormone and follicle-stimulating hormone. Biol. Reprod. 35: 347-352.

Gee, E. K., C. DeLuca, J. L. Stylski, and P. M. McCue. 2009. Efficacy of medroxyprogesterone acetate in suppression of estrus in cycling mares. J. Equine. Vet. Sci. 29: 140-145.

Gee, E. K., L. Gillespie, and C. F. Bolwell. 2012. Effect of oxytocin on suppression of oestrus in mares exhibiting normal oestrous cycles. NZ. Vet. J. 60: 189-193.

Ginther, O. J. 1990. Prolonged luteal activity in mares--a semantic quagmire. Equine. Vet. J. 22: 152-156.

Ginther, O. J. 1992. Reproductive biology of the mare: basic and applied aspects. $2^{\text {nd }}$ ed. Equiservices, Cross Plains, WI. p. 553. 
Ginther, O. J. 2012. The end of the tour de force of the corpus luteum in mares. Theriogenology. 77: 1042-1049.

Ginther, O. J., and M. A. Beg. 2009. Concentrations of circulating hormones normalized to pulses of a prostaglandin F2alpha metabolite during spontaneous luteolysis in mares. Theriogenology. 72: 1111-1119.

Ginther, O. J., and N. L. First. 1971. Maintenance of the corpus luteum in hysterectomized mares. Am. J. Vet. Res. 32: 1687-1691.

Ginther, O. J., M. C. Garcia, E. L. Squires, and W. P. Steffenhagen. 1972. Anatomy of vasculature of uterus and ovaries in the mare. Am. J. Vet. Res. 33: 1561-1568.

Ginther, O. J. et al. 2004. Comparative study of the dynamics of follicular waves in mares and women. Biol. Reprod. 71: 1195-1201.

Ginther, O. J., M. A. Siddiqui, and M. A. Beg. 2009. Progesterone responses to intravenous and intrauterine infusions of prostaglandin F2alpha in mares. Reprod. Fert. Develop. 21: 688-695.

Goff, A. K., D. Pontbriand, and J. Sirois. 1987. Oxytocin stimulation of plasma 15-keto13,14-dihydro prostaglandin F-2 alpha during the oestrous cycle and early pregnancy in the mare. J. Reprod. Fertility. Suppl. 35: 253-260.

Hedberg, Y., A. M. Dalin, P. Ohagen, K. R. Holm, and H. Kindahl. 2005. Effect of oestrous-cycle stage on the response of mares in a novel object test and isolation test. Reprod. Dom. Anim. 40: 480-488.

Hedberg, Y., A. M. Dalin, M. Santesson, and H. Kindahl. 2006. A preliminary study on the induction of dioestrous ovulation in the mare--a possible method for inducing prolonged luteal phase. Acta. Vet. Scan. 48: 12. 
Hodgson, D. et al. 2005. Effect of prolonged use of altrenogest on behaviour in mares. Vet. J. 169: 322-325.

Hooper, R. N., T. S. Taylor, D. D. Varner, and T. L. Blanchard. 1993. Effects of bilateral ovariectomy via colpotomy in mares: 23 cases (1984-1990). J. Am. Vet. Med. Assoc. 203: 1043-1046.

Hughes, J. P., A. C. Marcelo, and G. H. Stabenfeldt. 1985. Luteal phase ovulations: what are the options. Proc. An. Meet. Soc. Therio: 123-125.

Hughes, J. P. et al. 1979. Pyometra in the mare. J. Reprod. Fert. Suppl: 321-329.

Imboden, I. et al. 2006. Influence of immunization against GnRH on reproductive cyclicity and estrous behavior in the mare. Theriogenology. 66: 1866-1875.

Johnson, C. A., S. L. McMeen, and D. L. J. Thompson. 2002. Efects of multiple GnRH analogue (deslorelin acetate) implants on cyclic mares. Theriogenology. 58: 469471.

Johnson, C. A., D. L. Thompson, Jr., and J. A. Cartmill. 2003. Effects of deslorelin acetate implants in horses: single implants in stallions and steroid-treated geldings and multiple implants in mares. J. Anim. Sci. 81: 1300-1307.

Jorgensen, J. S., S. Vivrette, M. Correa, and R. Mansmann. 1996. Significance of the estrous cycle on athletic performance in mares. Am. Assoc. Equine. Pract. Proc. 42: $98-100$.

Kalbnik-Bradford, J., M. S. Ferrer, C. Belvins, and L. Beard. 2013. Marble-induced pyometra in an appaloosa mare. Clin. Therio. 5: 410. 
Keith, L. et al. 2013. Diestrus administration of oxytocin prolongs luteal maintenance and reduces plasma PGFM concentrations and endometrial COX-2 expression in mares. Theriogenology. 79: 616-624.

King, S. S., B. L. Douglas, J. F. Roser, W. J. Silvia, and K. L. Jones. 2010. Differential luteolytic function between the physiological breeding season, autumn transition and persistent winter cyclicity in the mare. Anim. Reprod. Sci. 117: 232-240.

Kutzler, M., and A. Wood. 2006. Non-surgical methods of contraception and sterilization. Theriogenology. 66: 514-525.

LeBlanc, M. 2011. Oxytocin. In: E. L. Squires, A. O. McKinnon, W. E. Vaala, D. D. Varner, editors, Equine reproduction. Wiley-Blackwell Publishing Ltd, Somerset, NJ. p. 1830-1835.

Lefranc, A. C., and W. R. Allen. 2004. Nonpharmacological suppression of oestrus in the mare. Equine. Vet. J. 36: 183-185.

Loy, R. G., and S. M. Swan. 1966. Effects of exogenous progestogens on reproductive phenomena in mares. J. Anim. Sci. 25: 821-826.

McCaughey, W. J., J. Hanna, and J. J. O'Brien. 1973. A comparison of three laboratory tests for pregnancy diagnosis in the mare. Equine. Vet. J. 5: 94-95.

McCracken, J. C., E; Lamsa, J. 1999. Luteolysis: A neuroendocrine-mediated event. Physiol. Rev. 79: 263-324.

McCue, P. M. 1997. Efficacy of synovex-S ${ }$ implants in suppression of estrus in the mare. J. Equine. Vet. Sci. 17: 327-329.

McCue, P. M. 2003. Estrus suppression in performance horses. J. Equine. Vet. Sci. 23: 342-344. 
McCue, P. M., V. J. Farquhar, and E. L. Squires. 2000. Effect of the GnRH agonist deslorelin acetate on pituitary function and follicular development in the mare. Proc. $46^{\text {th }}$. Conv. Am. Assoc. Equine. Pract: 355 .

McDonnell, S. M. 1993. Evaluation and modification of mare behavior problems. Proc. An. Meeting. Society. Theriogenology: 185-189.

McDonnell, S. M. 1997. Estrus cycle-related performance problems. J. Equine. Vet. Sci. 17: 196.

McDonnell, S. M. 2000. Reproductive behavior of stallions and mares: comparison of free-running and domestic in-hand breeding. Anim. Reprod. Sci. 60-61: 211-219.

McDonnell, S. M. 2005. Is it psychological, physical, or both? Proc. Annual. Conv. Am. Assoc. Equine. Pract. 4: 231-238.

McKinnon, A. O. et al. 1993. Predictable ovulation in mares treated with an implant of the GnRH analogue deslorelin. Equine. Vet. J. 25: 321-323.

McKinnon, A. O., W. J. Perriam, T. B. Lescun, J. Walker, and J. R. Vasey. 1997. Effect of GnRH analogue (Ovuplant), hCG and dexamethasone on time to ovulation in cycling mares. World. Equine. Vet. Rev. 2:6.

Molnar, M., J. Rigo, Jr., R. Romero, and F. Hertelendy. 1999. Oxytocin activates mitogen-activated protein kinase and up-regulates cyclooxygenase-2 and prostaglandin production in human myometrial cells. Am. J. Obstet. Gynecol. 181: 42-49.

Mumford, E. L., E. L. Squires, and E. Jochle. 1995. Use of deslorelin short-term implants to induce ovulation in cycling mares during three consecutive estrous cycles. Anim. Reprod. Sci. 39: 129. 
Nie, G. J. 2007. Estrous suppression. In: J. C. Samper, J. F. Pycock, A. O. McKinnon editors, Current therapy in equine reproduction. W. B. Saunders, Saint Louis, MO. p 26-31.

Nie, G. J., K. E. Johnson, T. D. Braden, and J. G. W. Wenzel. 2003. Use of an intrauterine glass ball protocol to extend luteal function in mares. J. Equine. Vet. Sci. 23: $266-273$.

Prendiville, D. J. et al. 1995. Immunization of heifers against gonadotropin-releasing hormone: antibody titers, ovarian function, body growth, and carcass characteristics. J. Anim. Sci. 73: 2382-2389.

Pryor, P., and A. Tibary. 2005. Management of estrus in the performance mare. Clin. Tech. Equine. Pract. 4: 197-209.

Rivera Del Alamo, M. M., T. Reilas, H. Kindahl, et al. 2008. Mechanisms behind intrauterine device-induced luteal persistence in mares. Anim. Reprod. Sci: 94106.

Rodgerson, D. H., J. K. Belknap, and D. A. Wilson. 2001. Laparoscopic ovariectomy using sequential electrocoagulation and sharp transection of the equine mesovarium. Vet. Surg: 30: 572-579.

Ross, M. W. 1991. Standing abdominal surgery. Vet. Clin. N. Am. Equine. Pract. 7: 627639.

Safir, J. M., R. G. Loy, and B. P. Fitzgerald. 1987. Inhibition of ovulation in the mare by active immunization against LHRH. J. Reprod. Fert. Suppl. 35: 229-237.

Samper, J. C. 2009. Equine breeding management and artificial insemination. 2nd ed. Saunders, Saint Louis, MO. p. 113-131 
Santos, V. G., E. M. V. Bettencourt, and O. J. Ginther. 2015. Long-term characteristics of idiopathic persistent corpus luteum in the mare. Theriogenology. 84: 242-251.

Shand, N., C. H. Irvine, J. E. Turner, and S. L. Alexander. 2000. A detailed study of hormonal profiles in mares at luteolysis. J. Reprod. Fert. Suppl: 271-279.

Sharp, D. C., M. J. Thatcher, M. E. Salute, and A. R. Fuchs. 1997. Relationship between endometrial oxytocin receptors and oxytocin-induced prostaglandin F2 alpha release during the oestrous cycle and early pregnancy in pony mares. J. Reprod. Fert. 109: 137-144.

Silvia, W. J., G. S. Lewis, J. A. McCracken, W. W. Thatcher, and L. Wilson, Jr. 1991. Hormonal regulation of uterine secretion of prostaglandin F2 alpha during luteolysis in ruminants. Biol. Reprod. 45: 655-663.

Simms, M. S. et al. 2000. Anti-GnRH antibodies can induce castrate levels of testosterone in patients with advanced prostate cancer. Br. J. Cancer. 83: 443-446.

Soloff, M. S., Y. J. Jeng, J. A. Copland, Z. Strakova, and S. Hoare. 2000. Signal pathways mediating oxytocin stimulation of prostaglandin synthesis in select target cells. Exp. Physiol. 85 Spec No: 51S-58S.

Squires, E. L., W. B. Stevens, D. E. McGlothlin, and B. W. Pickett. 1979. Effect of an oral progestin on the estrous cycle and fertility of mares. J. Anim. Sci. 49: 729735.

Stabenfeldt, G. H., J. P. Hughes, J. W. Evans, and D. P. Neely. 1974. Spontaneous prolongation of luteal activity in the mare. Equine. Vet. J. 6: 158-163. 
Starbuck, G. R., T. A. Stout, G. E. Lamming, W. R. Allen, and A. P. Flint. 1998. Endometrial oxytocin receptor and uterine prostaglandin secretion in mares during the oestrous cycle and early pregnancy. J. Reprod. Fert. 113: 173-179.

Stevenson, K. R., T. J. Parkinson, and D. C. Wathes. 1991. Measurement of oxytocin concentrations in plasma and ovarian extracts during the oestrous cycle of mares. J. Reprod. Fert. 93: 437-441.

Storer, W. A., D. L. Thompson, R. M. Gilley, and P. J. Burns. 2009. Evaluation of injectable sustained release progestin formulations for suppression of estrus and ovulation in mares. J. Equine. Vet. Sci. 29: 33-36.

Stout, T. A. 2011. Prostaglandins. In: E. L. Squires, A. O. McKinnon, W. E. Vaala, D. D. Varner editors, Equine reproduction. Wiley-Blackwell Publishing Ltd, Somerset, NJ. p. 1642-1647.

Stout, T. A., G. E. Lamming, and W. R. Allen. 1999. Oxytocin administration prolongs luteal function in cyclic mares. J. Reprod. Fert. 116: 315-320.

Stout, T. A., G. E. Lamming, and W. R. Allen. 2000. The uterus as a source of oxytocin in cyclic mares. J. Reprod. Fert. Suppl: 281-287.

Thompson, D. L. 2000. Immunization against GnRH in male species (comparative aspects). Anim. Reprod. Sci. 60: 459-469.

Tshewang, U., K. F. Dowsett, L. M. Knott, and T. E. Trigg. 1997. Preliminary study of ovarian activity in fillies treated with a GnRH vaccine. Aust. Vet. J. 75: 663-667.

Vallet, J. L., G. E. Lamming, and M. Batten. 1990. Control of endometrial oxytocin receptor and uterine response to oxytocin by progesterone and oestradiol in the ewe. J. Reprod. Fert. 90: 625-634. 
Vanderwall, D. K. 2012. Safe handling of reproductive hormones routinely used in equine practice. Clin. Therio. 4: 39-48.

Vanderwall, D. K. 2013. Prolonging function of the corpus luteum to suppress estrus in mares. In: Proc. 59 ${ }^{\text {th }}$. An. Conv. Am. Assoc. Equine. Pract. p 342-349.

Vanderwall, D. K., M. E. Agnew, M. R. Schnobrich, et al. 2012a. Effect of administration of oxytocin during diestrus on the duration of corpus luteum function and estrous behavior in cycling mares. Clin. Therio. 4:400

Vanderwall, D. K., and G. J. Nie. 2011. Estrus suppression. In: E. L. Squires, A. O. Mckinnon, W. E. Vaala, D. D. Varner, editors, Equine reproduction. WileyBlackwell Publishing Ltd, Somerset, NJ. p 1845-1853.

Vanderwall, D. K., D. M. Rasmussen, K. G. Carnahan, and T. L. Davis. 2012b. Effect of administration of oxytocin during diestrus on corpus luteum function and endometrial oxytocin receptor concentration in cycling mares. J. Equine. Vet. Sci. 32: $536-541$.

Vanderwall, D. K., J. L. Marquardt and G. L. Woods, 2007a. Use of a compounded longacting progestrone formulation for equine pregnancy maintenance. J. Equine. Vet. Sci. 27: 62-66.

Vanderwall, D. K., D. M. Rasmussen, and G. L. Woods. 2007b. Effect of repeated administration of oxytocin during diestrus on duration of function of corpora lutea in mares. J. Am. Vet. Med. Assoc. 231: 1864-1867.

Vanderwall, D. K., W. J. Silvia, and B. P. Fitzgerald. 1998. Concentrations of oxytocin in the intercavernous sinus of mares during luteolysis: temporal relationship with 
concentrations of 13,14-dihydro-15-keto-prostaglandin F2 alpha. J. Reprod. Fert. 112: 337-346.

Wesson, J. A., and O. J. Ginther. 1981. Influence of season and age on reproductive activity in pony mares on the basis of a slaughterhouse survey. J. Anim. Sci. 52: 119-129.

Wilsher, S., and W. R. Allen. 2011. Intrauterine administration of plant oils inhibits luteolysis in the mare. Equine. Vet. J. 43: 99-105.

Zhang, J., P. G. Weston, and J. E. Hixon. 1992. Role of progesterone and oestradiol in the regulation of uterine oxytocin receptors in ewes. J. Reprod. Fert. 94: 395-404. 